\title{
Dynamic elevation of the Cordillera, western United States
}

\author{
Anthony R. Lowry ${ }^{1}$ \\ Department of Geological Sciences, Indiana University, Bloomington
}

Neil M. Ribe

Laboratoire de Dynamique des Systemes Geologie, IPG, Paris

Robert B. Smith

Department of Geology and Geophysics, University of Utah, Salt Lake City

\begin{abstract}
We introduce a methodology that synthesizes topography, gravity, crustal-scale seismic refraction velocity, and surface heat flow data sets to estimate dynamic elevation, i.e., the topography deriving from buoyancy variations beneath the lithosphere. The geophysical data independently constrain the topographic effects of surface processes, crustal buoyancy, and thermal boundary layer thickness. Each of these are subtracted from raw elevation of the western U.S. Cordillera to reveal dynamic elevation that can exceed $2 \mathrm{~km}$ and is significant at $>95 \%$ confidence. The largest $(\sim 1000 \mathrm{~km}$ diameter $)$ of the dynamic elevation anomalies resembles a numerical model of a hypothetical Yellowstone hotspot swell, but the swell model does not account for all of the significant features seen in the dynamic elevation map. Other dynamic elevation anomalies are spatially correlative with Quaternary volcanism, but partial melt can contribute no more than a few hundred meters of elevation. Hence much of the dynamic elevation likely derives from other thermodynamic anomalies. Possible alternative mechanisms include both superadiabatic upwelling and adiabatic phase boundary deflections maintained by latent heat effects. Comparison of seismicity and volcanism to effective viscosity gradients, estimated from lithospheric flexural rigidity to facilitate the numerical swell model, suggests that tectonism focuses where lithosphere with negligible mantle viscosity abuts lithosphere with significant uppermost mantle viscosity.
\end{abstract}

\section{Introduction}

Topography of the actively deforming western U.S. Cordillera is characterized by high relief and regionally high elevation, typically exceeding $1.5 \mathrm{~km}$ (Plate 1). Intriguingly, much of the high elevation coincides with thin or attenuated continental crust, necessitating topographic support by anomalous buoyancy of the mantle [Suppe et al., 1975; Smith, 1978; Eaton, 1982; Jones et al., 1992 1996]. Mantle buoyancy has been attributed to one or more of three end-member processes: (1) variable thickness of the conductive thermal boundary layer, maintained by extensional thinning; (2) thermal het-

\footnotetext{
${ }^{1}$ Now at Department of Physics, University of Colorado, Boulder.

Copyright 2000 by the American Geophysical Union.

Paper number 2000JB900182.

0148-0227/00/2000JB900182\$09.00
}

erogeneity of the asthenosphere, generated by convective features such as the Yellowstone hotspot or other upwelling; and (3) thermodynamic and compositional variations associated with magmagenesis.

\subsection{Conductive Thermal Buoyancy}

McKenzie [1978] noted that extension thins the conductive thermal boundary layer and replaces it with lower-density convective material. Cordilleran lithosphere has extended by $\sim 250 \mathrm{~km}$ in late Cenozoic [ $W e r-$ nicke et al., 1988], and east-west extension continues at a rate of $\sim 1 \mathrm{~cm} \mathrm{yr}^{-1}$ [Bennett et al., 1999]. Correspondingly, rifted portions of the Cordillera exhibit elevated surface heat flow exceeding $80 \mathrm{~mW} \mathrm{~m}^{-2}$, as compared to $<60 \mathrm{~mW} \mathrm{~m}^{-2}$ in undeformed provinces to the east [Lachenbruch and Sass, 1978; Blackwell et al., 1991]. The variation of thermal boundary layer thickness implicit in the heat flow would significantly affect surface elevation. However, quantitative analyses suggest that thinning of the thermal boundary layer is not sufficient 

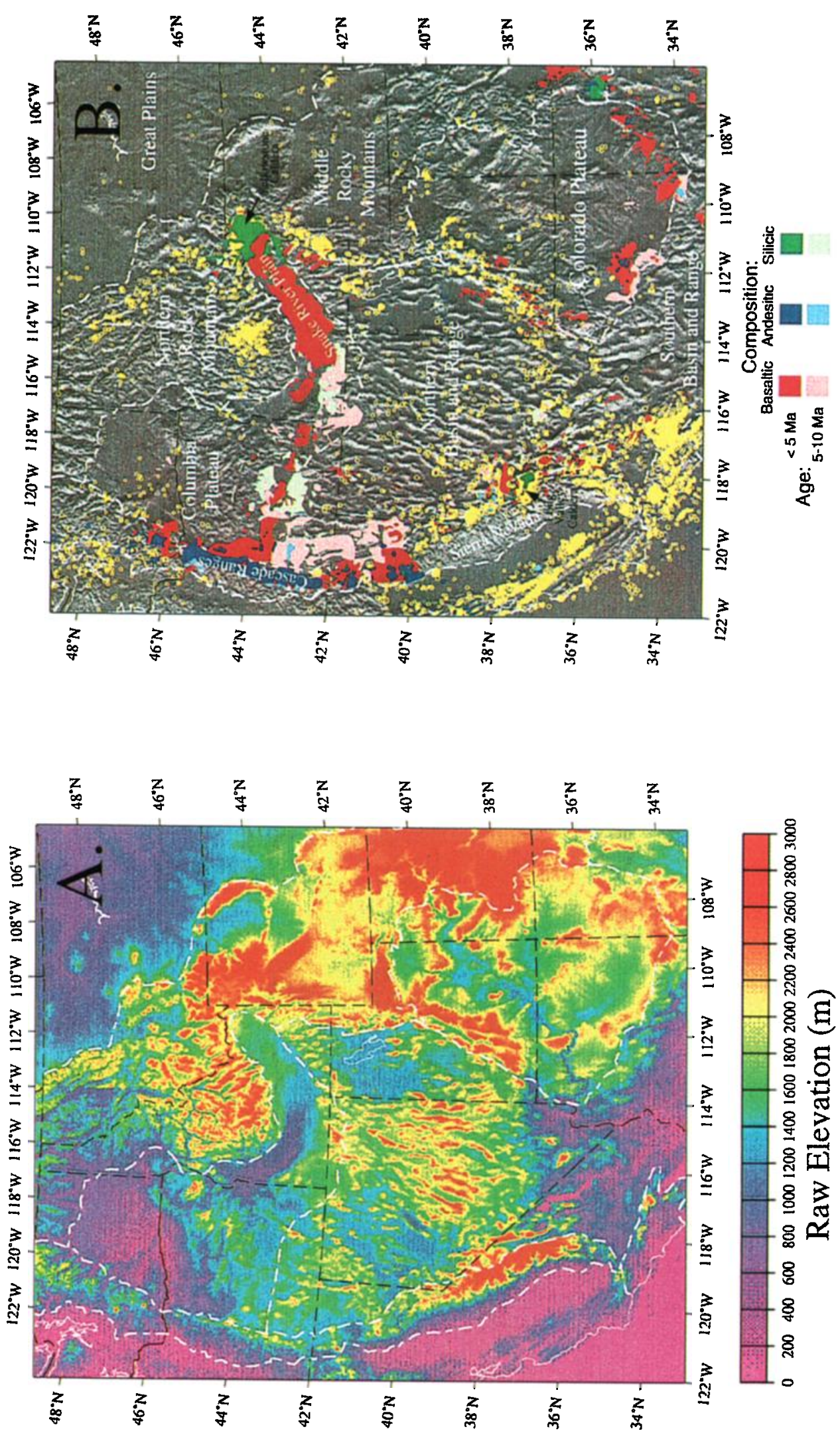

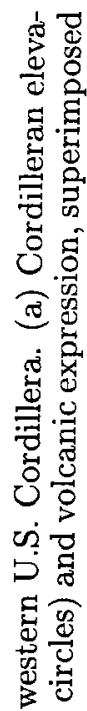

岑过

忌. 

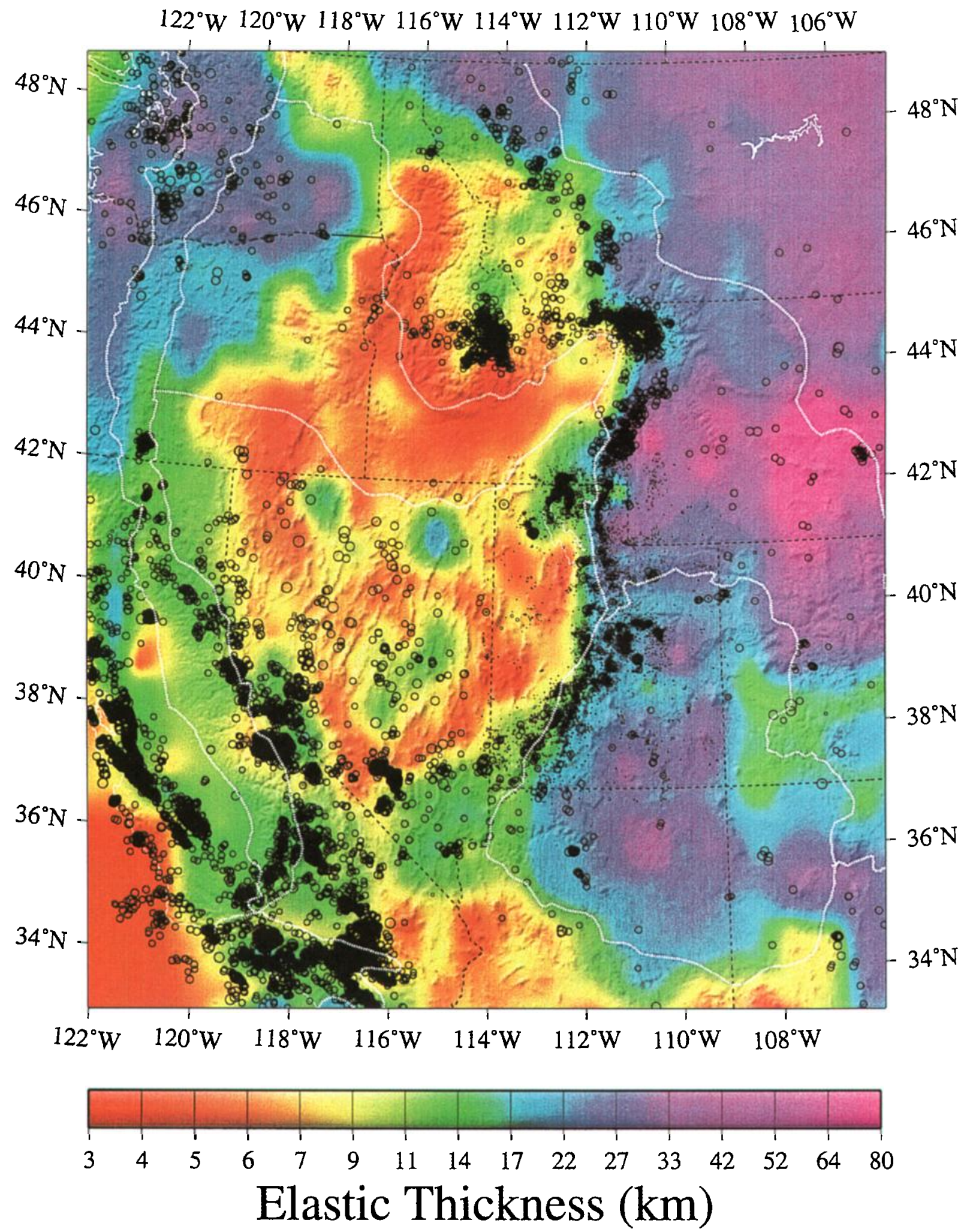

Plate 2. Effective elastic thickness $T_{e}$ of the Cordillera, from the relationship of gravity to topography. Seismicity (black dots) correlates with large gradients in lithospheric strength. 
to account for all mantle-derived elevation of the western United States [Lachenbruch et al., 1994; Saltus and Thompson, 1995].

\subsection{Hotspot Buoyancy}

Historically, the properties of hotspots have been defined from their expressions in oceanic regions. Characteristic features such as age progression of volcanic chains [Wilson, 1963] and bathymetric anomalies or "swells" [ Watts, 1976] were first recognized at midplate oceanic volcanoes such as Hawaii. The YellowstoneSnake River Plain (YSRP) volcanic field, a $\sim 700 \mathrm{~km}$ long, 50 to $100 \mathrm{~km}$ wide, curvilinear system stretching from north central Nevada to Yellowstone National Park (Plate 1b), is among the strongest candidates for a continental hotspot. Key elements of the YSRP's geophysical signature are consistent with a stationary asthenospheric melt source [Smith and Braile, 1994], including $\mathrm{K} / \mathrm{Ar}$ ages of silicic volcanism that track the North American plate motion vector [Armstrong et al., 1975]. The scale and amplitude of regional topographic and geoid anomalies are also similar to those of oceanic hotspots [Smith and Braile, 1994; Waschbusch and McNutt, 1994], leading several researchers to suggest that high elevation of the Yellowstone-Snake River Plain and the northern Basin-Range provinces corresponds to a Yellowstone swell supported by convective thermal buoyancy [Suppe et al., 1975; Smith, 1978; Pierce and Morgan, 1990; Parsons et al., 1994; Smith and Braile, 1994; Waschbusch and McNutt, 1994; Saltus and Thompson, 1995].

\subsection{Magmagenic Buoyancy}

Mantle magmagenesis entails the preferential melting and separation of $\mathrm{Fe}$ and $\mathrm{Al}$ silicates in a mantle aggregate. In a mantle partial melt, both the liquid phase and the solid residuum will be less dense than the original aggregate [Jordan, 1978; Fujii and Kushiro, 1977]. Various investigations have suggested a correlation of mantle-derived high elevation with magmagenesis in eastern California [Fliedner and Ruppert, 1996; Park et al., 1996; Wernicke et al., 1996], and Humphreys and Dueker [1994] postulated a magmagenic origin for Cordilleran high elevations based on the observation of very low $P$ velocity, requiring the presence of partial melt, in the Cordilleran upper mantle. If magmagenic buoyancy is sufficient to generate significant dynamic elevation, magmagenesis might also play a role in extensional processes via the lithospheric extensional stress generated by deep gravitational potential anomalies [Jones et al., 1996]. Structural analyses of the Cordillera suggest a broad space-time association between extension and volcanism [Christiansen and Lipman, 1972; Wernicke et al., 1987]. That relationship has been variously attributed to decompression melting driven by passive upwelling of the asthenosphere beneath extending lithosphere [Christiansen and McKee, 1978], thermal weak- ening of the crust following magmatic intrusion [Sonder et al., 1987], and asynchronous triggering of volcanism and extension by removal of a remnant slab from Mesozoic subduction [Axen et al., 1993]. Studies of rifts in other areas, particularly Africa, have postulated that extension is gravitationally driven by magmagenic uplift or "doming" [Burke and Whiteman, 1973; Şengör and Burke, 1978].

In actuality, high elevation of the western U.S. Cordillera probably derives from some combination of lithospheric extensional thermodynamics, convective thermal buoyancy, and magmagenic buoyancy. The objective of this paper is to better understand the relative importance of various contributors to western U.S. elevation. We attempt to isolate the topographic expression of each of the processes that influences elevation of the western U.S. Cordillera, using a combination of geophysical constraint, signal processing, and threedimensional geodynamic modeling. We first remove the topographic effects of various near-surface processes (e.g., erosion, deposition, volcanic construction, fault displacements, and strain) using an isostatic analysis of lithospheric loading. Next, we constrain the crustal contribution to surface elevation from regression of seismic refraction velocities to density. The effects of conductive geothermal variations are estimated from surface heat flow measurements. We also assess the contribution of a hypothetical Yellowstone hotspot swell with the aid of a numerical flow model of thermally driven upwelling. Finally, we consider the possible effects of magmagenic buoyancy using a simple melt model.

\section{Topographic Analysis}

The topography of the western U.S. Cordillera is among its most striking and enigmatic geophysical expressions (Plate 1). Many different processes have shaped the landscape, and often they occur at overlapping scales and depths, or have complex interrelationships. From a geodynamical perspective, we are particularly interested in observing and modeling the elevation response to sublithospheric mantle processes. Isolation of hotspot swells, for example, is relatively straightforward for oceanic lithosphere [e.g., Crough, 1983], but continental topography is dominated by processes that are typically much less well constrained than in oceans. These include the complex interplay of tectonic strain partitioning with erosion and deposition, the thickness and bulk composition of the crust, and thermal structure and composition of the mantle lithosphere. In the western United States, lithospheric terranes have diverse origins and crustal differentiation histories [e.g., Hoffman, 1989]. Following assembly, the lithosphere experienced rifting during the Precambrian, passive margin deposition through much of the Paleozoic, shortening and arc magmatism during Cretaceous and early Tertiary, and extension from late Tertiary on [e.g., Anderson, 1989]. The topographic expression has 
a complex dependence on all of these events, in addition to the modern active processes.

Prior investigations of Cordilleran topography have established that high elevations, particularly in the northern Basin-Range province, require a mantle buoyancy anomaly. However, none of these studies attempted a careful three-dimensional assessment of the source of lithospheric buoyancy. Existing analyses describe buoyancy from a single type of geophysical data [e.g., Jones et al., 1992; Humphreys and Dueker, 1994] and thereby underconstrain the relevant physical parameters of temperature, composition, and phase; or else they describe a very limited geographical area [e.g., Saltus and Thompson, 1995; Wernicke et al., 1996], thus limiting comparison with surface geospatial data that might be used to infer process.

\subsection{Deconvolution of Near-Surface and Subsurface Loads}

The first step in isolating mantle-derived elevation should be to remove the topographic effects of surface and near-surface processes such as erosion, deposition, fault displacements, volcanic construction, and lithospheric strain. Previous studies have used regional averaging or smoothing of the topography to attenuate the surface process topographic signal [Humphreys and Dueker, 1994; Smith and Braile, 1994; Waschbusch and McNutt, 1994; Jones et al., 1992, 1996]. However, smoothing introduces a bias error if the scale of the smoothing window is less than the wavelength at which isostatic response approaches an Airy state (typically 200 to $600 \mathrm{~km}$ in the western United States). Smoothing also degrades resolution, as subsurface loads can generate a topographic response at wavelengths as short as $50 \mathrm{~km}$.

As an alternative to smoothing, structures generated by surface processes can be segregated via analysis of isostatic response. The isostatic response to surface loads is distributed by flexure of the lithosphere, and consequently, these features are undercompensated by local subsurface mass (as observed from the relationship of gravity to topography; see Figure 1). On the other hand, mantle buoyancy anomalies will slightly "overcompensate" local topography (or more accurately, the topography undercompensates these mass anomalies). Hence one can decrease the near-surface "noise" by comparing elevations with gravitational potential and removing the undercompensated components of topography.

Surface and subsurface loads can be separated by exploiting spectral coherence and transfer functions of gravity and topography [Forsyth, 1985]. The relationship of Bouguer gravity to topography is modeled as the isostatic response of a thin elastic plate with density $\rho_{0}$ at the Earth's surface $(z=0), \rho_{1}$ at the base $(z=l)$, and $\rho(z)$ between (Figure 1). We assume an unknown Fourier amplitude of inital surface loading $H_{I}(\mathbf{k})$ at $z=0$ and subsurface loading $W_{I}(\mathbf{k})$ at some loading depth $z=z_{B}$ (corresponding to a density contrast $\left.\Delta \rho_{B}\right)$. Here $\mathbf{k}=\left(2 \pi / \lambda_{x}, 2 \pi / \lambda_{y}\right)$ is the two-dimensional wavenumber. The amplitudes of topography $H(\mathbf{k})$ and Bouguer gravity $B(\mathbf{k})$ depend on the initial loads as [Lowry and Smith, 1994]

$$
\begin{aligned}
H(\mathbf{k})= & {\left[\frac{\psi-\rho_{0}}{\psi}\right] H_{I}(\mathbf{k})-\left[\frac{\Delta \rho_{B}}{\psi}\right] W_{I}(\mathbf{k}) } \\
B(\mathbf{k})= & {\left[\frac{\phi \rho_{0}}{\psi}\right] H_{I}(\mathbf{k}) } \\
& -\left[\frac{\phi \Delta \rho_{B}}{\psi}+2 \pi G \Delta \rho_{B} \exp \left(-k z_{B}\right)\right] W_{I}(\mathbf{k})
\end{aligned}
$$

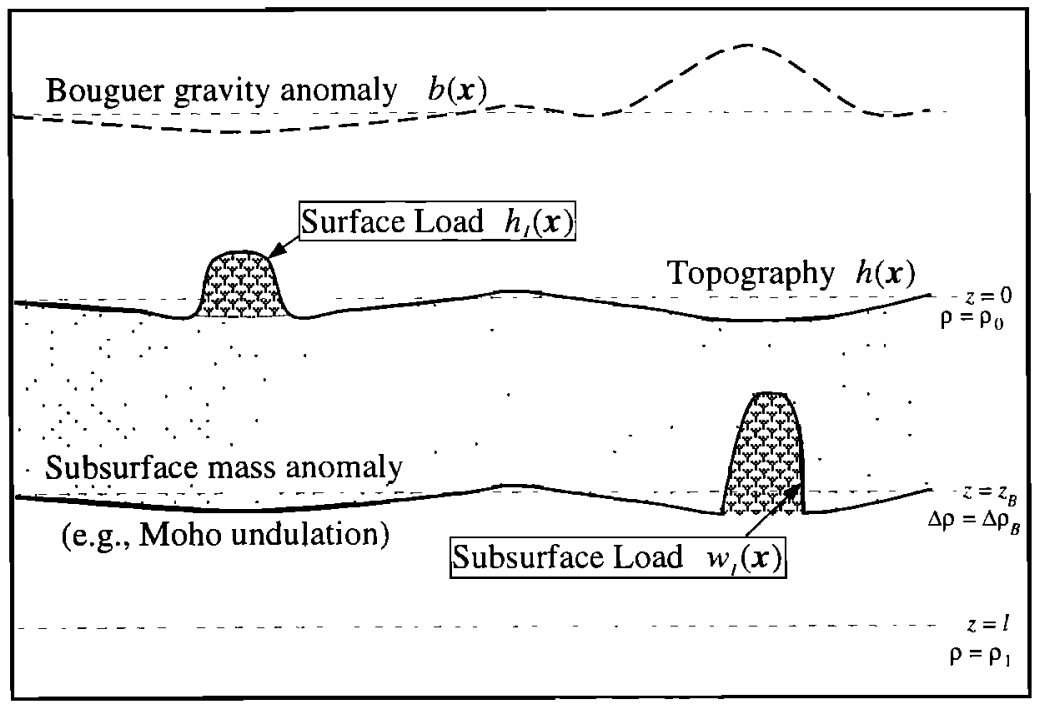

Figure 1. Relationship of Bouguer gravity to topography depends on location of the load. A subsurface load will be undercompensated by local topography, whereas surface loads are undercompensated by local mass anomalies. 
in which $k=|\mathbf{k}|, G$ is the gravitational constant, $g$ is the acceleration of gravity, $\psi=\rho_{1}+(D / g) k^{4}$, and $\phi=-2 \pi G \int_{-h}^{l}(\mathrm{~d} \rho / \mathrm{dz}) \exp (-k z) d z$. The linear equations (1) are solved for the two unknown load amplitudes given an assumed value of the flexural rigidity $D$, and then the topography is separated into amplitudes of a component due to surface loading $H_{T}(\mathbf{k})$ and a component due to subsurface loading $H_{B}(\mathbf{k})$ via

$$
\begin{aligned}
& H_{T}(\mathbf{k})=\left[\frac{\psi-\rho_{0}}{\psi}\right] H_{I}(\mathbf{k}), \\
& H_{B}(\mathbf{k})=H(\mathbf{k})-H_{T}(\mathbf{k}) .
\end{aligned}
$$

Conceptually, $h_{T}$ ( $\equiv \mathcal{F}^{-1}\left\{H_{T}\right\}$, where $\mathcal{F}\{\cdot\}$ is the Fourier transform operator), represents surface loads emplaced on top of the lithosphere plus the flexural isostatic response to those loads, while $h_{B}$, the topographic remainder, is the flexural isostatic response to mass anomalies within and beneath the lithosphere.

The flexural rigidity $D$ used for this calculation is determined by comparing the coherence function relating the observed $H$ and $B$ with coherence predicted from $H_{T}, H_{B}, B_{T}, B_{B}$ for various assumed values of $D$. $D$ has been estimated at a $50 \mathrm{~km}$ spacing over much of the western United States, using a maximum entropy-based coherence analysis of topography and Bouguer gravity [Lowry and Smith, 1994, 1995]. Estimates of the equivalent effective elastic thickness $T_{e}=\left[12\left(1-\nu^{2}\right) D / E\right]^{1 / 3}$ are shown in Plate 2. The estimation method assumes constant $D$ within a window of estimation, but in fact, $D$ varies significantly over short spatial scales. Consequently, the surface and subsurface components of topography were calculated by summing the load deconvolutions corresponding to the nearest estimates of $D$; the summation is linearly weighted by distance to those estimates in the spatial domain. The resulting estimate of $h_{T}$ is given in Plate $3 \mathrm{a}$.

The range of error in the estimate of surface load topography is also indicated in Plate 3a. Inaccuracies in the surface load elevation map derive principally from errors in the estimate of apparent flexural rigidity $D$ of the lithosphere. We estimated the standard error of surface load elevation by perturbing the surface load estimate using the standard error in $D$, which was derived from the error function as part of the coherence analysis [Lowry and Smith, 1994]. Also, this analysis used GTOPO30 topographic data, which in the United States are derived from digital elevation models with standard error $\leq 18 \mathrm{~m}$ [U.S. Geological Survey, 1993]. The total standard error in the surface process elevation estimate is the root-mean-square (RMS) sum of these two sources of error. Surface process elevation that is less than the one-sigma error is represented in Plate $3 \mathrm{a}$ as white with contours, elevations between onesigma and two-sigma are depicted with half-saturated color, and full color saturation indicates elevation that is significant at $95 \%$ confidence. Despite being approx- imately zero mean, surface process elevation exceeds two-sigma error for more than $55 \%$ of the map area.

Surface loads in the western United States (Plate 3a) result from dip-slip faulting, erosional and mechanical unloading, deposition, volcanic construction, and strain. At long wavelengths the surface load map predominantly reflects the viscoelastically supported elevation response to lithospheric strain. Contraction and extension associated with bends in the San Andreas fault appear as elevation highs and lows, respectively. Extensional necking lows and rift flank uplifts are prominent features at the edges of the Basin-Range province. At shorter wavelengths, dip-slip faults are manifested in both contractional Laramide structures and extensional faulting of the Basin-Range, and volcanic construction is apparent in the Cascades and other major volcanic centers. Of particular relevance to hotspot studies, the so-called "crescent" or "parabola" of high elevation surrounding the Snake River Plain that has been attributed to a Yellowstone swell [Pierce and Morgan, 1990; Smith and Braile, 1994] is composed mostly of surface loads.

\subsection{Crustal Mass Variations}

Subsurface loads result from heterogeneity of thermal, compositional, and phase buoyancy of the upper mantle and variations of thickness and average density of the crust. One example of a topographic anomaly with a crustal source is the Snake River Plain downwarp, which results from a dense mafic body intruded into the midcrust by the Yellowstone hotspot [Mabey, 1982; McQuarrie and Rogers, 1998]. We are primarily interested in mantle-derived topography, however, so as an additional step in processing, we would like to strip away the crustal contribution to elevation.

Jones et al. [1992] demonstrated that crustal mass can be approximated by relating crustal refraction seismic velocities to density. We perform a similar analysis here using 76 profiles from throughout the western United States, located as shown in Plate $3 \mathrm{~b}$. Compressional wave velocities were converted to density using the nonlinear velocity-density regression parameters of Christensen and Mooney [1995]. The regression densities $\rho_{p}(z)$ and crustal thickness $t_{c}$ were then used to calculate the crustal mass anomaly $\Delta m$ relative to a reference crustal density profile $\rho_{\text {ref }}(z)$, using

$$
\Delta m=\int_{t_{\mathrm{m} \text { u }}}^{\max \left\{t_{c}, t_{\mathrm{cref}}\right\}}\left[\rho_{p}(z)-\rho_{\mathrm{ref}}(z)\right] \mathrm{dz} .
$$

Here $\rho_{\text {ref }}(z)$ and $t_{\text {cref }}$ correspond to average crustal parameters tabulated by Christensen and Mooney [1995]; a different choice of reference crust would change the results only by introducing a static shift. The upper $\left(t_{\min }=\right) 5 \mathrm{~km}$ of the crust was ignored in (3) to reduce noise associated with velocity-density regression of the near-surface sediments. The map distribution of $\Delta m$ was interpolated using a kriging algorithm with first- 
order linear drift [e.g., Davis, 1986]. This interpolation procedure has the dual advantage of providing an "optimal" representation of Gaussian-distributed data and an estimate of standard error that varies according to sampling and local statistical properties of the measurements. Amplitudes $\Delta M \equiv \mathcal{F}\{\Delta m\}$ of the interpolated crustal mass anomaly were used to calculate amplitudes of the corresponding crustal component of topography $H_{c}$ via the thin plate approximation of flexural isostatic response:

$$
H_{c}=-\frac{\Delta M}{\psi} .
$$

As with the surface load calculation, variable flexural rigidity $D$ in the study area was accommodated by a spatial domain summation over the nearest estimates of $D$. The corresponding estimate of elevation due to crustal buoyancy $h_{c}$ is shown in Plate $3 \mathrm{~b}$.

There are two sources of error in the estimated crustal contribution to elevation $h_{c}$. One corresponds to errors in crustal velocity estimates by refraction profiles, stemming from variable quality of the seismic data and inversion methods used, effects of three-dimensional structure on profiles, sparse sampling, and an ambiguity between thickness and internal velocity of refracting layers. This first source of error is reflected in the semivariogram, and so we assigned uncertainty associated with the velocity structure according to the kriging estimate of standard error in $\Delta m$. Error associated with the regression of velocity to density was estimated by integrating the standard errors quoted by Christensen and Mooney [1995] over the crustal thickness. The total standard error depicted in Plate $3 \mathrm{~b}$ is the RMS sum of these two estimates of error. One-sigma error in the crustal elevation estimate ranges from $\sim 500$ to $800 \mathrm{~m}$; $\sim 50 \%$ of the map area exceeds the one-sigma error and $\sim 20 \%$ exceeds two-sigma error. Note that the estimated crustal elevation that exceeds two-sigma error is not necessarily any less uncertain than in those areas which are depicted white with contours: Full color saturation, in this instance, simply means that the crustal mass differs from that of "average" continental crust at $>95 \%$ confidence.

\subsection{Conductive Thermal Variations}

The raw elevation (Plate 1a) that is not accounted for by surface loading (Plate 3a) and crustal mass variations (Plate $3 \mathrm{~b}$ ) corresponds to the elevation response to mantle buoyancy. At this point in the analysis, we would like to begin to distinguish elevation signals according to their root processes. Namely, how much of the topography is a consequence of variable thickness of the thermal boundary layer, how much is due to thermal variations in the asthenosphere (e.g., hotspots and other convective processes), and how much results from the thermodynamics of magmagenesis?

To assess the contribution due to variable thickness of the thermal boundary layer, we are interested only in the portion that is steady state (i.e., unperturbed by dynamic processes such as convection). Steady state conductive geotherms can be constrained, to first order, from reliable surface heat flow measurements. Surface heat flow $q_{s}$ is a notoriously noisy measure of the deep conductive geotherm, as it also reflects perturbations by hydrologic flow, variable crustal heat production, refractory effects around sedimentary basins, and advective effects associated with intrusion and exhumation. Nevertheless, these measurements contain significant information about lithospheric thermal structure. We used measurements from the current U.S. compilation of heat flow data first described by Blackwell et al. [1991], supplemented by the global compilation of Pollack et al. [1993]. Duplicate data and outliers $(<15$ and $>160 \mathrm{~mW} \mathrm{~m}^{-2}$ ) were removed. The surviving measurements were interpolated using kriging with first-order linear drift. We then designed a continuation filter [after Mareschal et al., 1985] to identify and remove heat flow anomalies with sources at crustal depths.

We map $q_{s}$ into geothermal variation using a onedimensional solution of the governing equations for conductive heat transfer. Our starting point is the classic error function solution for an impulsively cooled halfspace,

$$
T(z)=T_{s}+\left(T_{r}-T_{s}\right) \operatorname{erf}\left(\frac{z}{l_{\text {con }}}\right)
$$

where $T_{s}$ is surface temperature, $T_{r}\left(=1300^{\circ} \mathrm{C}\right)$ is the mean reference temperatire at which the conductive geotherm intersects the adiabat, and $l_{\text {con }}$ is a thermal length scale. If the half-space is undergoing uniaxial strain at a constant rate $\dot{\epsilon}$,

$$
l_{\text {con }}=\left\{\frac{2 \kappa}{\dot{\epsilon}}[1-\exp (-2 \dot{\epsilon} t)]\right\}^{1 / 2},
$$

where $\kappa$ is thermal diffusivity. Note that this reduces to the familiar expression for half-space cooling $l_{\text {con }}=$ $\sqrt{2 \kappa t}$ when $\dot{\epsilon}=0$. A uniformly extending half-space is a valid approximation for the western United States, where heat transfer is dominated by extensional advection [Lachenbruch and Sass, 1978; Mareschal and Bergantz, 1990].

When perturbed by radiogenic heat production that decreases exponentially with depth, (5) becomes

$$
\begin{aligned}
T(z)= & T_{s}+\frac{A_{0} l_{\mathrm{rad}}^{2}}{K}\left[1-\exp \left(-\frac{z}{l_{\mathrm{rad}}}\right)\right] \\
& +\left(T_{r}-\frac{A_{0} l_{\mathrm{rad}}^{2}}{K}-T_{s}\right) \operatorname{erf}\left(\frac{z}{l_{\mathrm{con}}}\right)
\end{aligned}
$$

in which $K$ is thermal conductivity, $l_{\text {rad }}(=5400 \pm 1700$ $\mathrm{m}$ ) is an empirically-derived characteristic depth for distribution of radiogenic elements [Lachenbruch and Sass, $1978]$ and $A_{0}$ is heat production per unit volume at the Earth's surface, which we interpolated from measure- 


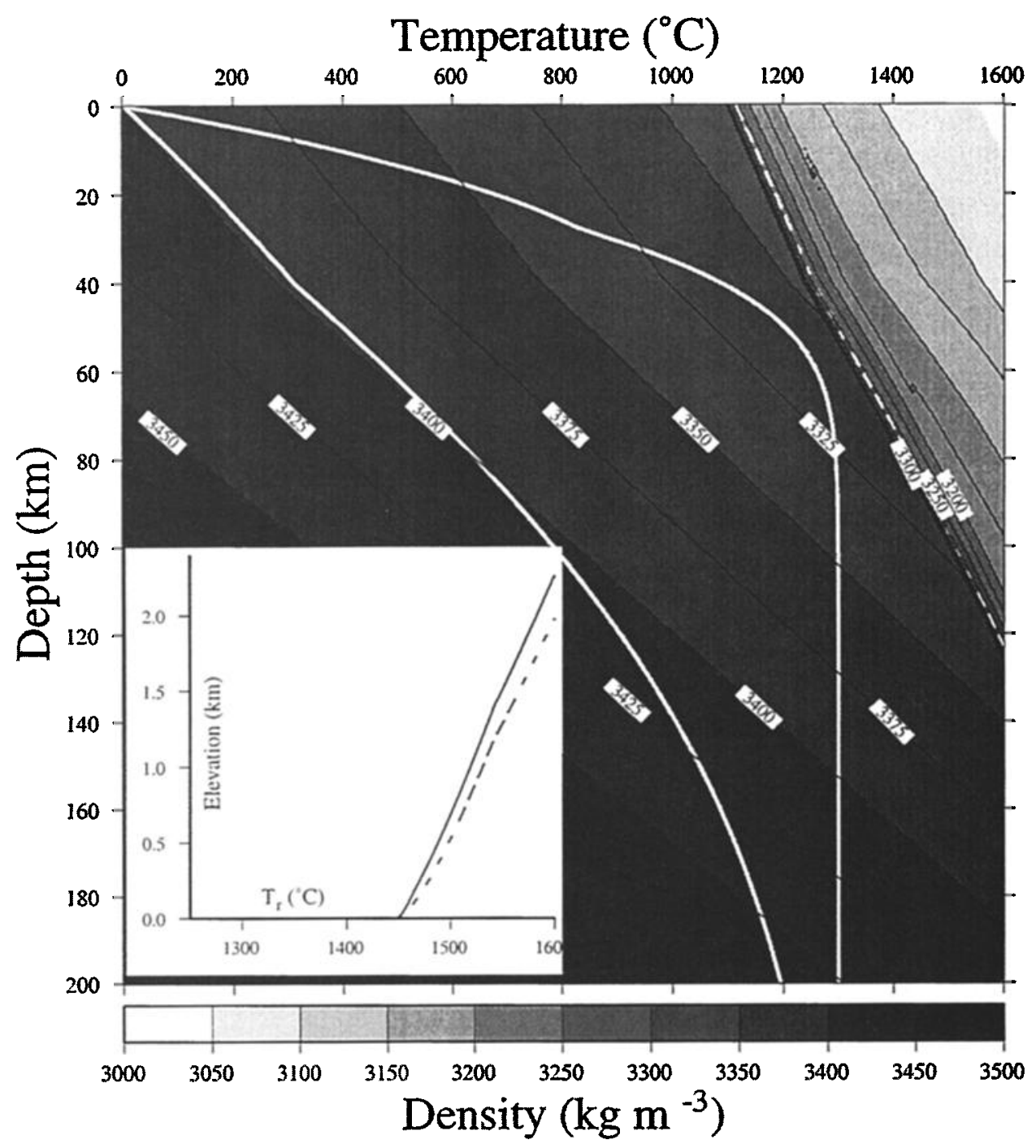

Figure 2. Mantle density variation from combined effects of equations of state and melting. The range of geotherms calculated for the western U.S. Cordillera is shown as thick white lines. Thick black line is MORB-type solidus; dashed white line is $5 \%$ melt saturation. Inset shows magmagenic elevation in the Airy limit, in function of reference temperature $T_{r}$. Solid line is $5 \%$ melt saturation; dashed line: $0 \%$ melt saturation.

ments in the Pollack et al. [1993] and Blackwell et al. [1991] compilations. Surface heat flow is given by:

$$
\begin{aligned}
q_{s} & =\left.K \frac{\partial T}{\partial z}\right|_{z=0} \\
& =A_{0} l_{\mathrm{rad}}\left(1-\frac{2 l_{\mathrm{rad}}}{\sqrt{\pi} l_{\mathrm{con}}}\right)+\frac{2 K\left(T_{r}-T_{s}\right)}{\sqrt{\pi} l_{\mathrm{con}}} .
\end{aligned}
$$

Equivalently,

$$
l_{\mathrm{con}}=\frac{2\left[K\left(T_{r}-T_{s}\right)-A_{0} l_{\mathrm{rad}}^{2}\right]}{\sqrt{\pi}\left(q_{s}-A_{0} l_{\mathrm{rad}}\right)} .
$$

Thermal transfer properties $K$ and $\kappa$ vary with depth as a function of both compositional layering and pressure/temperature conditions. Crustal rocks generally have low thermal conductivity $\left(\sim 2-3 \mathrm{~W} \mathrm{~m}^{-1}{ }^{\circ} \mathrm{K}^{-1}\right.$ at $\left.290^{\circ} \mathrm{K}\right)$ that decreases with temperature as $K=$ $1 /(a+b T)$ [Siepold, 1998]. Mantle aggregates have higher $K(\sim 5)$ at surface $p$ and $T$ and a similar temperature dependence to that of crustal rocks but with a potentially significant component of radiative transfer in addition to the lattice conductivity such that $K=1 /(a+b T)+c T^{3}$. We used $a=0.28, b=3.16 \times 10^{-4}$ for the crust (corresponding to the mean for crustal rocks in the Siepold [1998] compendium), and $a=0.073$, $b=4.54 \times 10^{-4}$, and $c=1.96 \times 10^{-10}$ for the mantle [after Kukkonen et al., 1999]. Then we solved numerically for the unique geotherm satisfying (5)-(9) that was continuous at the moho. The range of geotherms calculated for the western U.S. Cordillera is depicted in Figure 2. 
The relationship of density to thermally induced crystal lattice dynamics, i.e., thermal expansion $\alpha(T, z)$, is relatively well-constrained from both theory and observation in the case of olivine. Density $\rho$ is related to pressure and temperature by the equations of state [e.g., Reynard and Price, 1990]:

$$
\begin{gathered}
\left(\frac{\alpha}{\alpha_{0}}\right)=\left(\frac{\rho}{\rho_{0}}\right)^{-\delta_{T}}, \\
\delta_{T}=-\left(\frac{1}{K_{T} \alpha}\right)\left(\frac{\partial K_{T}}{\partial T}\right)_{p},
\end{gathered}
$$

in which $\alpha_{0}$ is the thermal expansion coefficient at a reference $(p, T)\left(2.8 \times 10^{-5} \mathrm{~kg} \mathrm{~m}^{-3}{ }^{\circ} \mathrm{K}^{-1}\right.$ at $300^{\circ} \mathrm{K}$ and 1 atm [Bouhifd et al., 1996]), $\rho_{0}$ is density at the reference $(p, T)$ (here $\left.3400 \mathrm{~kg} \mathrm{~m}^{-3}\right), K_{T}$ is bulk modulus $\left(=1.3 \times 10^{11}\right.$ at reference $\left.(p, T)\right)$, and $\delta_{T}$ is the Anderson-Gruneisen parameter ( $=5.5$ to 6.0 for upper mantle minerals above the Debye temperature) and is approximately independent of $p$. Density as a function of temperature and depth, using (10) and (11), is also shown in Figure 2.

Geotherms from the numerical solution of (5)-(9) were converted to a mass anomaly via

$$
\Delta m=\int_{t_{c}}^{\infty}\left[\rho(T, z)-\rho\left(T_{a v}, z\right)\right] d z,
$$

in which $T_{a v}$ is an averaged geotherm for the area studied. Thermal expansion within the crust was ignored because, ideally, this should be reflected in the crustal seismic velocity and thickness used to estimate crustal mass variations. The mantle mass anomaly associated with variable thickness of the thermal boundary layer was then converted to its corresponding elevation anomaly via (4). The result is depicted in Plate 3c, with error indicated by color saturation as in previous elevation estimates.

Error in the estimate of thermal boundary layer elevation can arise from six different sources: (1) Surface heat flow measurements are subject to sampling limitations and unmodeled shallow hydrologic and refractory perturbations, as well as processes of mechanical and magmatic advection; these are attenuated by continuation filtering to remove effects of crustal heat sources and so are upper-bounded by the standard error of the kriging interpolation. (2) Sampling errors for measurements of surface radiogenic heat production are represented by the standard error from kriging of $A_{0}$ measurements. (3) The characteristic depth for exponential decay of radiogenic heating, $l_{\text {rad }}$, was estimated from linear regression of the relationship between surface heat flow $q_{s}$ and heat production $A_{0}$; standard error of $\pm 1700 \mathrm{~m}$ was derived from the statistics of the regression. (4) The mean temperature at the intersection of the conductive and adiabatic geotherms, $T_{r}$, is assumed to have standard error of $\pm 50^{\circ} \mathrm{K}$. (5) Mea- surements of thermal conductivity $K$ of olivine-bearing rocks in the Siepold [1998] compilation have standard errors of $\pm 25 \%$; crustal rocks also have about $\pm 25 \%$ variability when all of the likely crustal compositions are included. (6) Standard error in the thermal expansion coefficient $\alpha$ of olivine-bearing rocks is about $\pm 10 \%$ [Bouhifd et al., 1996].

One-sigma errors in the estimate of thermal boundary layer elevation were calculated independently for each of the possible error contributors. Most of these errors map nonlinearly into elevation, in which case the larger of the two possible elevation errors was adopted. All six error estimates were combined in RMS sum to produce the confidences depicted in Plate 3c. The errors are skewed, with larger error on lower elevations because the nonlinear mapping of heat flow to mass is more sensitive to errors when geotherms are cold. Although the elevation estimate is approximately zero mean, more than $50 \%$ of the map area exceeds the one-sigma error.

\section{Dynamic Elevation Estimate}

Elevation contributions from surface loads (Plate 3a), crustal mass anomalies (Plate $3 \mathrm{~b}$ ), and mantle thermal anomalies (Plate 3c) were subtracted from the observed topography (Plate 1a). The remainder (Plate $3 \mathrm{~d}$ ) approximates the elevation response to asthenospheric buoyancy, i.e., the dynamic elevation. Dynamic elevation in the western United States contributes a very significant fraction to the total signal: In the northern Basin-Range province the magnitude is comparable to that of the raw topography. Error in the estimate of dynamic elevation is simply the RMS sum of errors associated with the various measurements and parameters that factored into estimation of surface process, crustal, and thermal boundary layer contributions to elevation. Confidence in the dynamic elevation estimate is indicated by color saturation, similar to Plates $3 a-3 c$. Nearly $60 \%$ of the map area exceeds one-sigma error; $\sim 25 \%$ exceeds $95 \%$ confidence.

\section{A Numerical Model of Yellowstone Plume Buoyancy}

Having established that a portion of Cordilleran elevation is dynamic, we should begin to consider which geodynamical processes might be responsible. In this section we use a three-dimensional (3-D) numerical convection model to estimate the dynamic elevation that could be produced by a mantle plume beneath the western U.S. Cordilleran lithosphere. The numerical model consists of a rectangular box filled with a fluid whose viscosity $\eta$ varies as a function of depth and temperature according to

$$
\eta=\eta_{r} \exp \left[\frac{\left(H^{*}+\rho_{0} g h V\right)\left(T_{r}-T\right)-\rho_{0} g z V T_{r}}{R T T_{r}}\right]
$$



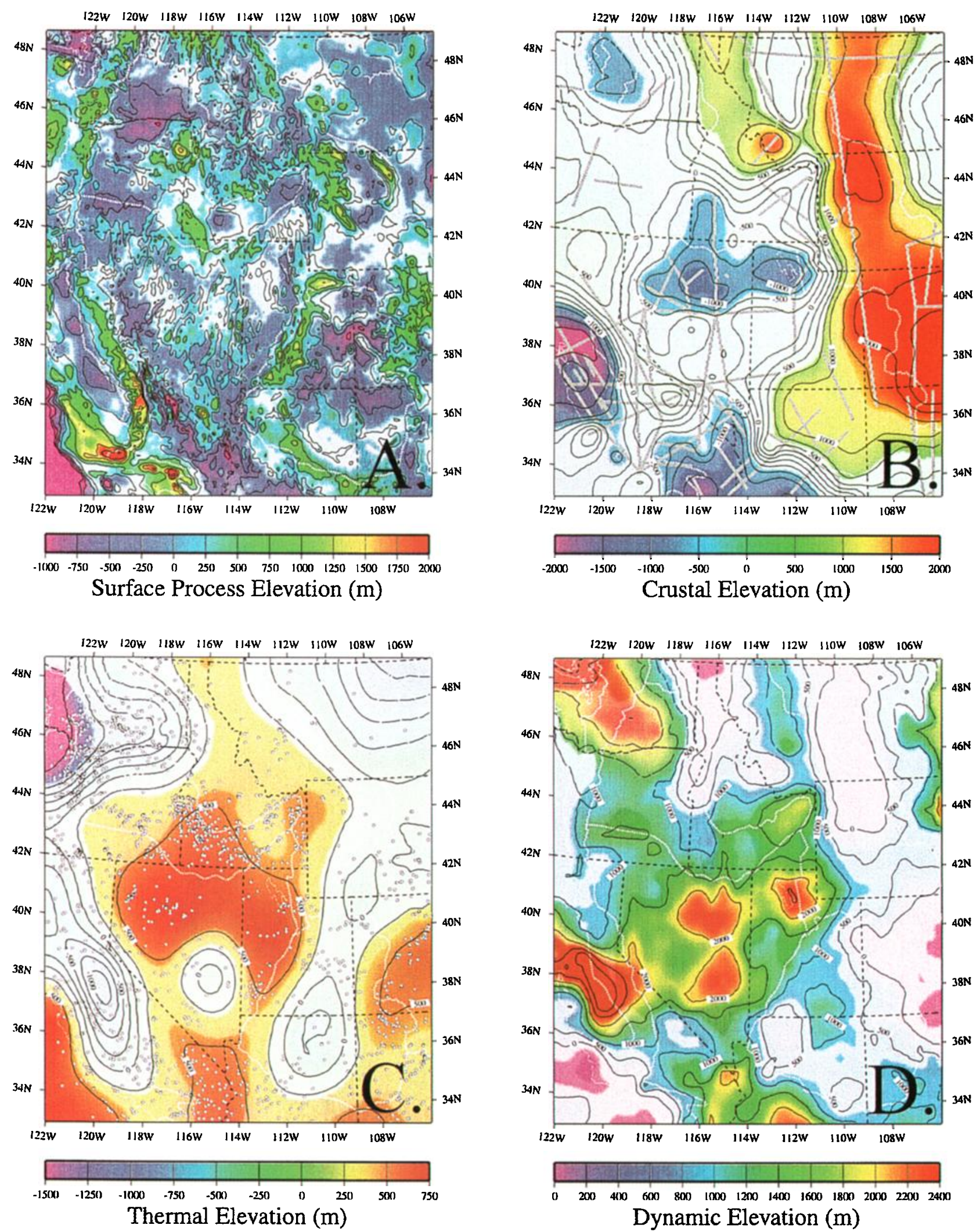

Plate 3. Separated components of Cordilleran elevation. Confidence in each estimate is indicated by color saturation (white, elevation estimate is $\leq 68 \%$ confidence limit; half saturation. estimate is between $68 \%$ and $95 \%$ confidence; full color saturation, estimate exceeds $95 \%$ confidence). (a) Elevation from surface load processes and their isostatic response. (b) Elevation from the isostatic response to crustal mass variations. Grey lines indicate crustal seismic refraction profiles used to constrain the estimate. (c) Elevation from variations in thickness of the thermal boundary layer. White circles are the distribution of surface heat flow measurements. (d) Dynamic elevation (i.e., elevation derived from asthenospheric buovancy') of the western U.S. Cordillera. 

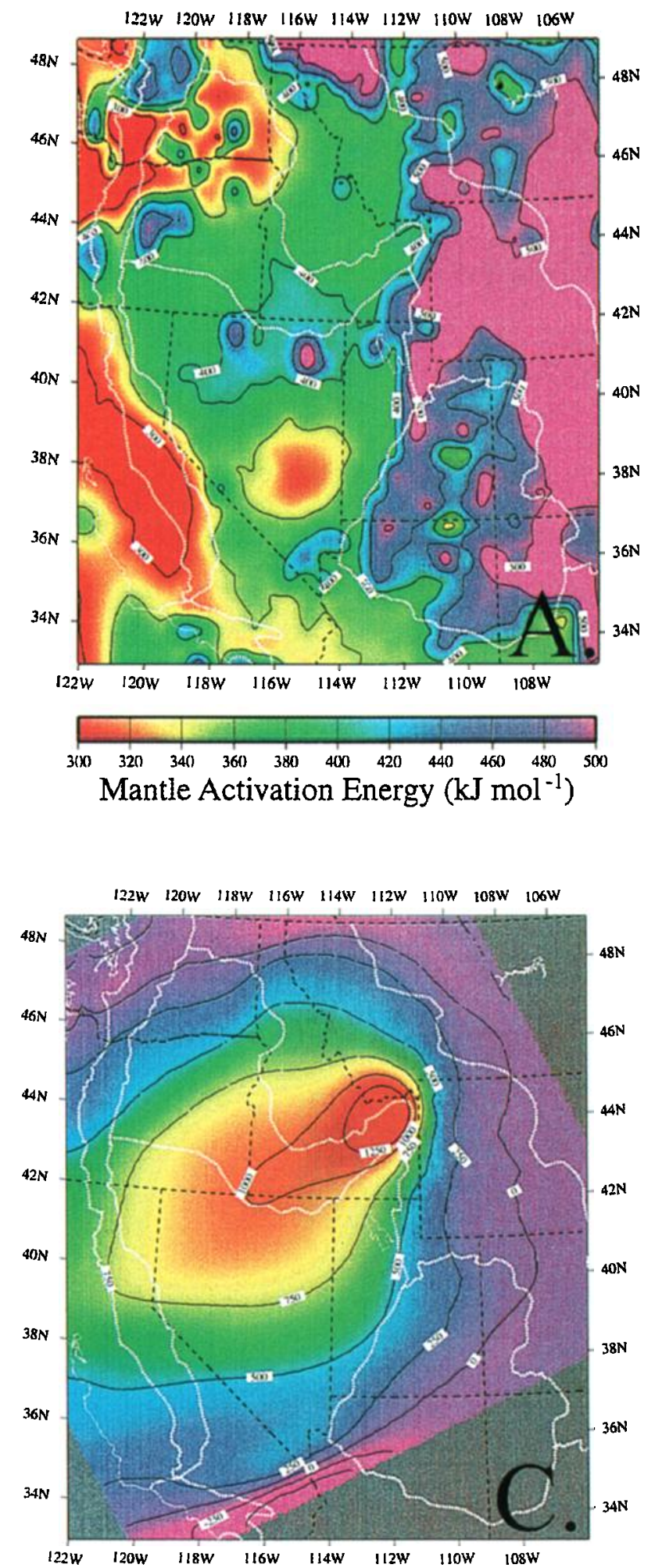

$122 \mathrm{~W}$ l20w $118 \mathrm{~W}$ 116w $114 \mathrm{~W}$ 112W $110 \mathrm{~W}$ 108w

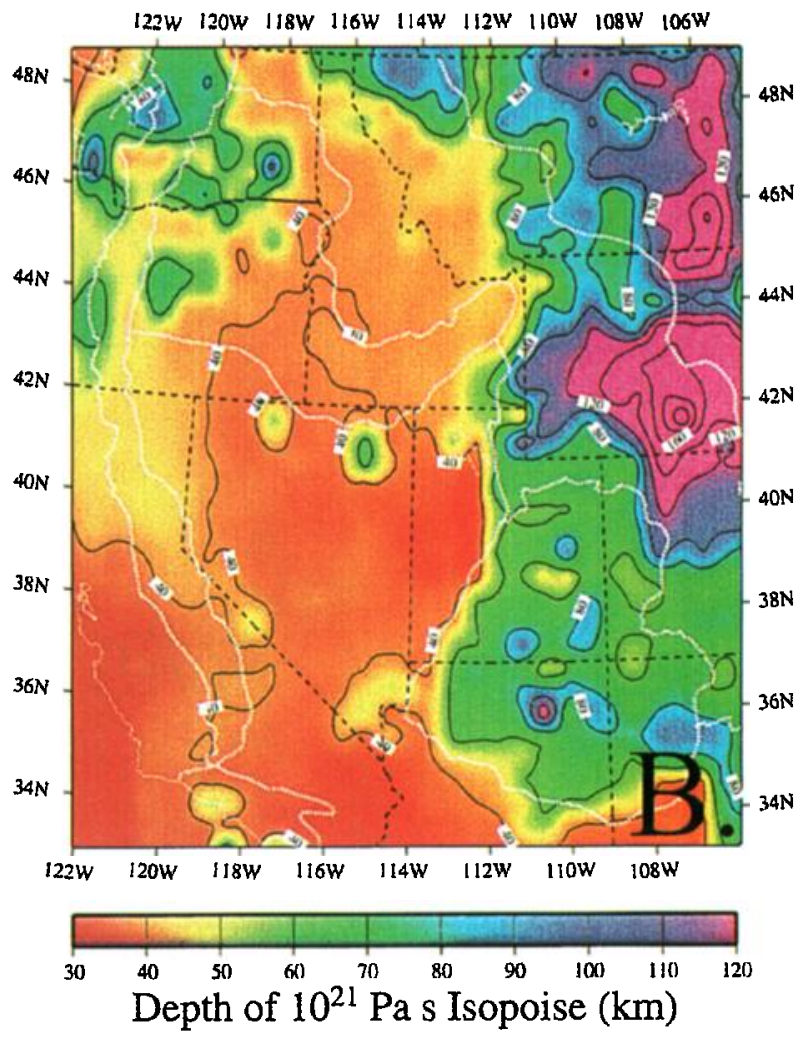

Depth of $10^{21} \mathrm{~Pa} \mathrm{~s}$ Isopoise $(\mathrm{km})$

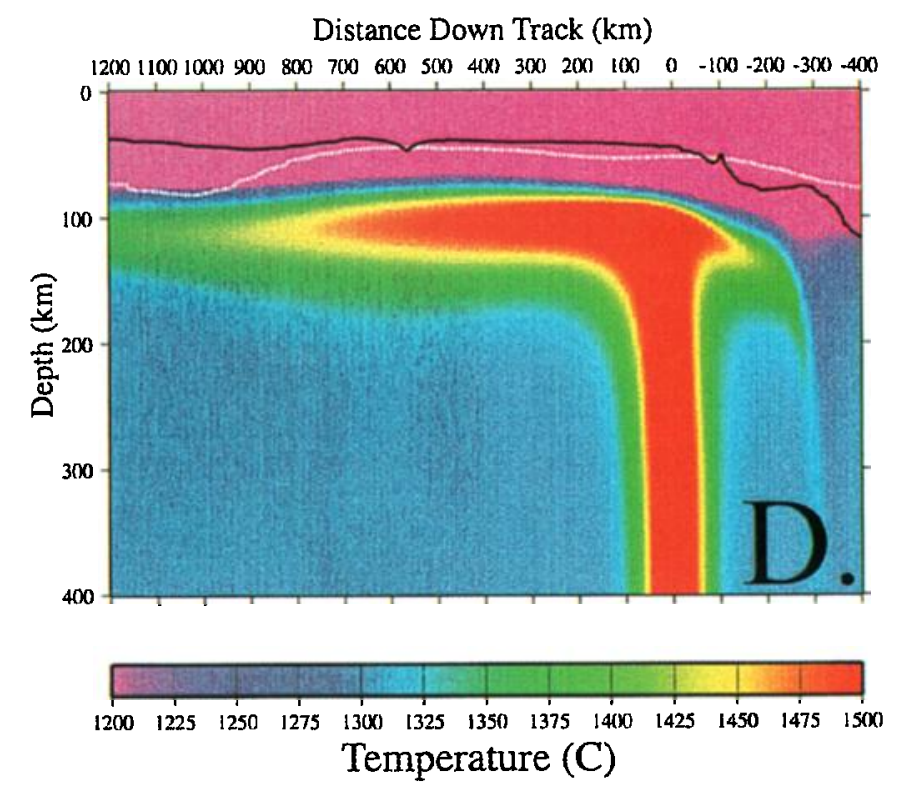

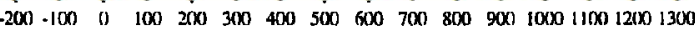
Swell Elevation (m)

Plate 4. Cordilleran lithospheric properties and modeling of a hypothetical Yellowstone hotspot swell. (a) Effective activation energy $H_{m}^{*}$ of the Cordillera, from the relationship of flexural rigidity $D$ to surface heat flow. (b) Depth of the $10^{21} \mathrm{~Pa} \mathrm{~s}$ isopoise of viscosity. (c) Numerical model of swell elevation for the variable-thickness lithosphere depicted in part $b$ and $3 \times 10^{-16}$ $\mathrm{s}^{-1}$ uniaxial extension southwest of the plume. (d) Cross section of temperature field along the track of the hotspot. White line is the $1000{ }^{\circ} \mathrm{C}$ isotherm from surface heat flow; black line is depth to the $10^{21}$ isopoise $l$. 
where $H^{*}$ is activation energy, $V$ is the activation volume, $\eta_{r} \equiv 10^{21} \mathrm{~Pa} \mathrm{~s}$ is a reference viscosity, and $\rho_{0} \equiv 3300 \mathrm{~kg} \mathrm{~m}^{-3}$ is a reference density. Motion of the upper surface with velocity $U(x)$ generates a shear flow inside the box. A thermal plume is generated by a temperature anomaly on the bottom of the box and interacts with the shear flow as it rises to the base of the lithosphere. Further details of the model can be found in Appendix A.

Oceanic swell characteristics include symmetry about the hotspot track, an $\sim 1000 \mathrm{~km}$ cross-sectional width, elongation in the direction of plate motion, and decreasing elevation downstream of the hotspot [Crough, 1983]. These features are consistent with predictions by flow models of the dynamic response to buoyancy of hot plume material sheared by the motion of a viscous plate [e.g., Ribe and Christensen, 1994]. The rheological properties and geodynamics of the western U.S. Cordillera are distinct from those of oceanic lithosphere, however. Significant differences include (1) nonuniform velocity relative to a fixed mantle because of extension of the Basin-Range province and (2) variable thickness of viscous lithosphere in the various tectonic provinces. Hence we have modified the model method of Ribe and Christensen [1994] to more accurately approximate the Cordilleran environment. The buoyancy flux of the plume is $4800 \mathrm{~kg} \mathrm{~s}^{-1}$, and the easternmost lithosphere moves at velocity $U=3.5 \mathrm{~cm} \mathrm{yr}^{-1}$. However, uniaxial NE-SW lithospheric extension at a rate of $3 \times 10^{-16}$ $\mathrm{s}^{-1}$ (corresponding to $\sim 1 \mathrm{~cm} \mathrm{yr}^{-1}$ opening across the Basin-Range province) is imposed downstream (SW) of Yellowstone. Also, the viscous lithosphere has a nonuniform thickness approximating that expected for the western U.S. Cordillera. The latter feature of the model is motivated by the expectation that buoyant plume material will flow along gradients of lithospheric thickness, thereby "ponding" preferentially beneath regions of thinner lithosphere [Sleep, 1997].

Lithospheric thickness variations are represented as lateral viscosity variations derived from flexural rigidity $D$ and surface heat flow $q_{s}$ via an algorithm detailed in Appendix B. The resulting lithospheric thickness $l$ (defined as the depth at which effective viscosity is $10^{21}$ $\mathrm{Pa} \mathrm{s}$ ) incorporates spatial variability of both temperature and material properties. Material properties are expressed in terms of an effective mantle activation energy $H_{m}^{*}$, depicted in Plate 4a. Heterogeneous $H_{m}^{*}$ is necessary because variations in lithospheric strength integrated in $D$ cannot be accommodated by geothermal variations alone. Estimated lithospheric thickness $l$ is depicted in Plate 4b. Swell topography (Plate 4c) modeled with the nonuniform lithospheric viscosity structure is not axisymmetric and is less axially elongate than when a uniform lithospheric thickness is used. Ponding of plume material results in steepened swell elevation gradients where the lithospheric thickness gradient is steep, particularly at the Basin-Range transition to the Colorado Plateau and middle Rocky Mountains. However, first-order features such as the overall amplitude and width of the swell are approximately the same as would be predicted for uniform lithosphere.

Plate $4 \mathrm{~d}$ depicts an axial cross section of the thermal structure responsible for the modeled swell elevation. Also shown are the depths along section of the $10^{21} \mathrm{~Pa} \mathrm{~s}$ isopoise $l$ and the $1000^{\circ} \mathrm{C}$ isotherm estimated from surface heat flow (i.e., the steady state geotherm before it has been perturbed by the modeled plume dynamics). The plume flow dynamics are not greatly affected by lithospheric structure along track of the hotspot because the upper mantle has virtually no strength downtrack and the plume is just beginning to interact with stronger lithospheric mantle to the northwest. Surface heat flow is unperturbed in this model because the timescale of conduction through the lithosphere is $\sim 100 \mathrm{Myr}$, and the model does not account for magmatic advection. However the plume does influence the basal thermal boundary layer structure. Geothermal structure from Cordilleran surface heat flow was used to define the initial conditions of the model (see Appendix A), but the thermal boundary layer is much thinner downtrack, particularly at around $900-1200 \mathrm{~km}$, after perturbation by convective flow.

\section{Processes of Mantle Buoyancy}

In the course of the analysis thus far, we have estimated the contribution of thermal boundary layer buoyancy from surface heat flow measurements, and we have numerically modeled the expression of convective thermal buoyancy from a hypothetical Yellowstone plume. While both of these processes can contribute significantly to elevation, each by itself, and indeed both of them combined, are inadequate to explain the mantlederived elevation of the Cordillera. Compositional and melt buoyancy has also been hypothesized to contribute to Cordilleran mantle elevation. We will examine this possibility more closely using a simple model of magmagenesis. Finally, we will consider some other alternative models for generating dynamic elevation.

\subsection{Thermal Boundary Layer Buoyancy}

Extensional thinning of the thermal boundary layer, invoked by Eaton [1982] and Jones et al. [1992], does contribute to Cordilleran high elevation: Topography derived from thermal boundary layer thickness (Plate 3c) accounts for at least $15 \%$ of the total isostatic response to mantle buoyancy, a lower-bound estimate from averaging over all wavenumbers $\mathbf{k}>0$ the real portion of the transfer function relating mantle and thermal elevation. Nevertheless, extensional thinning of the thermal boundary layer is not sufficient to offset the effects of crustal thinning, even given the relatively large uncertainties on these estimates (compare Plates $3 \mathrm{~b}$ and $3 c$ ), and hence it is not nearly sufficient to account for all 
of the mantle buoyancy. Several other studies similarly conclude that mantle-derived elevation of the northern Basin-Range cannot be attributed solely to extensional thinning of the thermal boundary layer [Lachenbruch et al., 1994; Saltus and Thompson, 1995].

\subsection{Hotspot Swell Buoyancy}

Our geodynamical model of Yellowstone hotspot swell elevation (Plate 4c) improves upon previous plumelithosphere interaction models with the inclusion of independently constrained variable lithospheric thickness, lithospheric strain, and buoyancy of melt-depleted residuum in the numerical modeling. The model produces high dynamic elevation in the northern BasinRange, and like the observed anomaly in Plate 3d, the modeled swell is elongate in the direction of North American plate motion. Also, the edges of the modeled swell match reasonably well with steep gradients in the estimated dynamic elevation anomaly. However, the amplitude of the modeled swell anomaly is less than half that of the dynamic elevation, and while the model is consistent with the largest of the western U.S. dynamic elevation anomalies, it does not reproduce other smaller features. The model would explain only $\sim 25 \%$ of the estimated dynamic elevation map.

The model fit could be improved by increasing the buoyancy flux and/or by introducing additional complexities into the plume-lithosphere interaction model. The Cordilleran elevation anomaly is much larger than the $\sim 1000 \mathrm{~m}$ peak swell elevation beneath Hawaii, but the buoyancy flux used for this model was only slightly greater than that of the Hawaii model by Ribe and Christensen [1994] (4800 versus $4100 \mathrm{~kg} \mathrm{~s}^{-1}$ ). Also, the Yellowstone model assumes constant plume buoyancy flux and ignores plate boundary interactions, but the absence of YSRP volcanic expression before $17 \mathrm{Ma}$ argues against simple, steady state boundary conditions. The abrupt onset of YSRP anatectic volcanics and effusive plateau basalts has led some researchers to suggest the Yellowstone hotspot initiated as a large "plume head" in mid-Miocene [Parsons et al., 1994; Zoback et al., 1994; Saltus and Thompson, 1995], while others infer the hotspot's surface expression was disrupted by the subducting Juan de Fuca slab [Geist and Richards, 1993]. One could modify the numerical model to accommodate plate boundary kinematics or plume initiation. However, much of the significant misfit between the model and estimated dynamic elevation is associated with smaller-scale anomalies in areas that should be unperturbed by Yellowstone hotspot dynamics.

\subsection{Magmagenic Buoyancy}

Dynamic elevation that varies on scales of the order of a few times the lithospheric thickness is consistent with growth of Rayleigh-Taylor instabilities [e.g., Turcotte and Schubert, 1982]. These instabilities can develop as a gravitationally driven flow response to a denser layer (e.g., the thermal boundary layer) overlying a more buoyant layer. Some of the Cordilleran high elevation that is not attributable to Yellowstone hotspot buoyancy correlates with other volcanic fields (compare, for example, Plate 1b with Plate 3d), with the clearest examples occurring in the Salton Sea region of the eastern California volcanic belt and just south of the southern boundary of the Colorado Plateau. This suggests that a portion of Cordilleran dynamic elevation is related to magmagenesis, consistent with Tackley and Stevenson's [1993] model of Rayleigh-Taylor instabilities driven by melt buoyancy and Humphreys and Dueker's [1994] subsequent hypothesis of melt buoyancy modulated by compositional variations.

Magmagenesis entails a thermodynamic anomaly, a small percentage of basaltic melt, and compositional alteration of the residuum. Each of these can enhance the aggregate buoyancy. Mantle olivines hover around $\left(\mathrm{Mg}_{0}{ }_{9} \mathrm{Fe}_{0.1}\right)_{2} \mathrm{SiO}_{4}$ composition, and a magmatically fertile aggregate will also contain dense garnet and pyroxene constituents; the denser ferrous and aluminum silicates are first to be consumed by basalt production [Jordan, 1978, 1981]. The resulting melt is significantly less dense than the parent rock [Fujii and Kushiro, 1977]. The aggregate density depends on the percentage of partial melt and composition of the melt and residuum. Composition depends in turn upon pressure, temperature, and composition of the source rock [Presnall et al., 1979; McKenzie and Bickle, 1988], while melt fraction is limited by processes of melt migration [Stolper et al., 1981]. The density of the residuum depends principally on the amount of iron and aluminum removed by melting, expressed in terms of the molar fraction of $\mathrm{Al}_{2} \mathrm{O}_{3}\left(X_{\mathrm{Al}}\right)$ and the molar ratio of iron to magnesium $R=X_{\mathrm{Fe}} /\left(X_{\mathrm{Fe}}+X_{\mathrm{Mg}}\right)$ as:

$$
\rho=\rho(p, T)\left[1-\frac{\partial \ln \rho_{0}}{\partial X_{\mathrm{Al}}} \Delta X_{\mathrm{Al}}+\frac{\partial \ln \rho_{0}}{\partial R} \Delta R\right] .
$$

The partial derivative terms are estimated to be -0.70 and 0.32 , respectively [Jordan, 1981].

We have calculated an example relationship between density of a fertile garnet lherzolite, temperature, and depth, using (10), (11), and (14), laboratory measurements of $\rho(p, T)$ of basaltic melts [Fujii and Kushiro, 1977], and the empirical relations for chemistry of melting 18-22; $\mathrm{A} 2-\mathrm{A} 3$ in the work of McKenzie and Bickle [1988]. The result is shown in Figure 2. The density variation depends only on equations of state below the solidus (indicated by the thick solid black line) and is dominated by the melt phase and preferential extraction of dense components above the solidus. The aggregate density change between the solidus and the partial melt saturation point (here taken to be $5 \%$ ) is about equivalent to that for a $500^{\circ} \mathrm{K}$ change in temperature. However, integration of a magmagenic buoyancy anomaly yields an elevation response that is dominated by depletion of the residuum as opposed to buoyancy of the 
melt itself, as depicted for the Airy-isostatic limit in inset in Figure 2. The elevation anomaly from a partial melt that saturates at $5 \%$ (solid line in inset) is only slightly larger than that which would result from compositional depletion alone (dashed line indicating $0 \%$ melt saturation).

One will note that the geotherms derived earlier from surface heat flow never intersect the dry solidus depicted in Figure 2. This may indicate that asthenospheric temperatures in volcanic regions locally exceed those for a typical isentropic adiabat, as implied by the variable reference temperature $T_{r}$ used to examine magmagenic buoyancy in the Figure 2 inset. Alternatively, it is possible that western U.S. volcanism is facilitated by anomalous mantle water content. The McKenzie and Bickle [1988] melt relations used to generate Figure 2 are specific to mid-ocean ridge basalt (MORB)-type melting of a dry lherzolite. However, water can lower the solidus temperature by several hundred degrees and is generally thought to be the agent for subduction volcanism such as that of the Cascade range. Western U.S. volcanism outside the Cascades may still exploit water remnant from Laramide subduction processes, for example. However, the MORB to ocean island basalt (OIB) compositions of most U.S. Cordilleran basaltic volcanism imply that thermodynamics plays a greater role than oxygen fugacity.

One may also observe from the inset of Figure 2 that compositionally controlled variability in density of the uppermost mantle conceivably could suffice to explain the entire "dynamic elevation" signal in Plate $3 \mathrm{~d}$. However, other geophysical measurements of the uppermost mantle exhibit variability exactly opposite that which would be expected if the northern Basin-Range were more basalt-depleted than the Colorado Plateau and Rocky Mountain provinces to the east. A dense garnet lherzolite composition would have lower $P$ wave seismic velocity [Jordan, 1981] and lower activation energy $H^{*}$ [e.g., Poirier, 1991] than a peridotite, but the eastern stable platform has relatively high $P$ velocity [Humphreys and Dueker, 1994] and effective activation energy $H_{m}^{*}$ (Plate 4a). We infer from this that the dynamic elevation anomaly is truly dynamic rather than compositional. Moreover, given that partial melt variations probably contribute only slightly to elevation, we expect that some sort of asthenospheric thermodynamic anomaly is required.

\subsection{Alternative Sources of Dynamic Buoyancy}

There are several other possible sources for Cordilleran dynamic elevation in addition to those discussed thus far. These include (1) another form of superadiabatic upwelling (different than, or in addition to, the Yellowstone hotspot modeled previously), (2) phase boundary deflections as a result of passive (strain-driven) vertical flux, and (3) deeper buoyancy (i.e., from below the $660 \mathrm{~km}$ phase transition of spinel to perovskite and magnesiowustite). Given that the influence of the Yellowstone hotspot is effectively limited to the northern Basin-Range and melt buoyancy is likely inadequate to generate the dynamic elevation observed along the southern boundary of the Colorado Plateau, one or more of these mechanisms may play a significant role.

Savage and Sheehan [2000] suggest that patterns of shear wave splitting polarization in the Cordillera are most consistent with strains due to a large vertical upwelling centered approximately in the middle of the northern Basin-Range province. They cite a preliminary version of the dynamic elevation map (Plate $3 \mathrm{~d}$ ) to bolster their hypothesis. Upwelling centered in the Basin-Range might be expected in passive response to rifting if, for example, extensional divergence could not be accommodated by return flow of material above the 410 (e.g., because of impedance by subducted slab). In order to generate dynamic elevation, however, the upwelling would have to be superadiabatic. In a perfectly isentropic mantle, upwelling would not generate the thermal anomaly needed to produce dynamic elevation. Extension-driven upwelling would be superadiabatic if, for example, the deeper material tapped by upwelling were, by chance, anomalously hot. This mechanism is appealing because most of the significant dynamic anomalies coincide with the rifted northern and southern Basin-Range provinces and also because MORB-type volcanism in the Cordillera appears to require a thermodynamic "push."

On the other hand, an adiabatic (passive) upwelling can also generate dynamic topography via deflection of phase boundaries by latent heat effects [e.g., Christensen, 1998]. Surface topographic response to a 660 deflection would be small ( $\lesssim 500 \mathrm{~m}$ in the Airy limit) and negative for upwelling [Christensen, 1998], so is an unlikely candidate for the anomalies observed here. Deflection of the 410 would produce dynamic elevation of the correct sign, and the large $(\sim 45 \mathrm{~km})$ deflection imaged by Dueker and Sheehan [1997] at the transition from the extending Basin-Range to the stable Wyoming craton would equate to $>2 \mathrm{~km}$ of dynamic elevation in the Airy limit, assuming a density contrast of $200 \mathrm{~kg}$ $\mathrm{m}^{-3}$ [Matsui, 1999]. To our knowledge, no one has closely examined the dynamic topography that might be generated by deflection of the 410 . However Podladchikov et al. [1994] examined the dynamic topography that would be generated by the $(\sim 60 \mathrm{~km})$ garnet-spinel transition (which also has positive Clapeyron slope), and they estimated a transient uplift effect of $\sim 500$ m. Phase boundary deflection by extension-driven upwelling is another appealing mechanism for passive generation of dynamic elevation, given the distribution of anomalies in Plate $3 \mathrm{~d}$. However, we caution that there are significant uncertainties in both the experimental 
measurements of phase transition parameters and the velocity structures used to translate $P$ to $S$ conversion times into depths.

Finally, dynamic elevation can arise from deeper (i.e., mid and lower mantle) buoyancy anomalies. Pari and Peltier [2000] estimate dynamic topography of several kilometers from mantle velocity structure (though their calculations effectively include thermal boundary layer buoyancy). However, their isostatic response kernels suggest that surface response of a viscous Earth diminishes rapidly with depth of the buoyancy anomaly and is nearly negligible for spherical harmonic degree $l \geq 8$ $(\lesssim 2500 \mathrm{~km}$ wavelength) at $\sim 800 \mathrm{~km}$ depth. Response kernels are sensitive to viscosity structure, which remains somewhat uncertain. However, on the small scale of anomalies considered in this study, deeper buoyancy is unlikely to be a significant contributor.

\section{Discussion}

It is worth noting that the original purpose of this analysis was simply to isolate and numerically model the Yellowstone hotspot swell, and only after careful consideration of the results did we conclude that dynamic elevation in the Cordillera has more complex origins. The analysis performed here permits us to conclude to $>95 \%$ confidence that the mantle component of buoyancy includes a large $(\sim 2 \mathrm{~km})$ dynamic contribution. Extensional thinning of the conductive thermal boundary layer certainly contributes to elevation, but not enough to generate the observed mantle anomaly. However, while a part of the dynamic elevation signature is similar in location and appearance to the flow model of Yellowstone dynamics, this by no means provides a "smoking gun" as to the presence or absence of a Yellowstone swell, and moreover, we can offer little insight into the relative contributions of convection, magmatism, superadiabatic upwelling, and adiabatic phase boundary dynamics to Cordilleran elevation. There are physical and geophysical observations to suggest that any or all of these processes may play a role.

Also, we must stress that some of the conclusions reached herein depend critically on the assumed value of uppermost mantle thermal conductivity. The temperature-dependent thermal conductivity relation used in this analysis yields $K=2$ to $2.8 \mathrm{~W} \mathrm{~m}^{-1}{ }^{\circ} \mathrm{K}^{-1}$ in the mantle, as opposed to $K=5$ corresponding to thermal conductivity of olivine at surface conditions. Had we used $K=5$ in our calculations, the dynamic elevation in Plate $3 \mathrm{~d}$ would disappear to within uncertainties. It has been suggested that radiative transfer (i.e., electromagnetic transfer) of heat might be sufficiently nonnegligible at upper mantle conditions to increase $K$ to its surface value [e.g., Morgan, 1993]. However, independent estimates of $K=2-3 \mathrm{~W} \mathrm{~m}^{-1}{ }^{\circ} \mathrm{K}^{-1}$ at relevant $(p, T)$ conditions from experimental measurements [Katsura, 1995] and from phonon lifetimes using infrared reflectance spectography [Hofmeister, 1999], when coupled with theoretical considerations limiting the radiative transfer contribution to less than half the total conductivity below $2000^{\circ} \mathrm{K}$ [Hofmerster, 1999], lend confidence to our assertion that a dynamic contribution to Cordilleran elevation is required.

There are, nevertheless, problems with the geothermal estimates that are not fully addressed in the error analysis. In particular, we note that heat flow has been lowered by subduction processes near the Pacific and Juan de Fuca plate boundaries, and this (essentially dynamic) effect results in underestimation of thermal boundary layer buoyancy (Plate 3c), overestimation of dynamic topography (Plate $3 \mathrm{~d}$ ), and underestimation of effective mantle activation energy $H_{m}^{*}$ (Plate 4a). Consequently, dynamic elevation estimates in those areas exhibiting $H_{m}^{*}<300 \mathrm{~kJ} \mathrm{~mol}^{-1}$ (and perhaps even those $<350 \mathrm{~kJ} \mathrm{~mol}^{-1}$ ) should be viewed with some skepticism.

Other significant implications of this work relate to the root processes of tectonism and volcanism in the U.S. Cordillera. The estimation of lithospheric viscosity and effective activation energy described in Appendix B is relegated to an almost ancillary status in this paper, but these have very far-reaching implications. We have noted previously [Lowry and Smith, 1995] that there are striking correlations between the loci of seismicity, volcanic centers and large gradients in effective elastic thickness $T_{e}$ of the lithosphere. When $T_{e}$ is combined with thermal structure to estimate rheology, it becomes apparent that the seismicity and volcanism is focused at locations where the $10^{21}$ isopoise of viscosity diverges significantly from the moho depth (Plate $4 \mathrm{~b}$ ), that is, at the boundaries separating lithosphere with negligible mantle strength from stable lithosphere with high uppermost mantle viscosity. Moreover, the variation of effective activation energy $H_{m}^{*}$ would suggest that stable lithosphere is defined as much or more by intrinsic material properties as by transient thermal properties, providing a tidy explanation for why consecutive deformation events will often reactivate the same blocks of lithosphere, despite separation by timescales over which temperatures should equilibrate.

Finally, it is becoming increasingly clear that modern deformation of the western U.S. Cordillera results from a combination of horizontal boundary conditions imposed by right-lateral shear at the Pacific-North American plate boundary and vertical normal stresses owing to deep buoyancy heterogeneities [Jones et al., 1996; Shen-Tu et al., 1998; Flesch et al., 2000]. The magnitude of the deviatoric stress produced by buoyancy anomalies is sensitive to the depth of support of surface topography (with deeper buoyancy heterogeneities inducing larger stress moments) and to viscosity structure in the Earth. Jones et al. [1996] based their estimates of deviatoric stress in the western United States on the conservative assumption that all relevant buoyancy variations occur in the lithospheric mantle and that het- 
erogeneity decreases linearly with depth. Our analysis indicates that a substantial fraction of western U.S. elevation is rooted in asthenospheric buoyancy anomalies, implying that deviatoric stresses could be substantially greater than previously estimated.

\section{Conclusions}

Disentanglement of the buoyancy sources responsible for western U.S. elevation is an important step toward understanding Cordilleran deformation for two reasons: (1) deeply rooted buoyancy contributes significantly to the lithospheric stresses that drive deformation and (2) the processes that generate mantle buovancy (variable thickness of the thermal boundary layer, thermal convection, passive upwellings, and magmagenesis) are potentially important expressions of tectonism independent of their buoyancy signatures. Analysis and modeling of a variety of geophysical signals, including topography, gravity, heat flow, and crustal seismic velocity, indicate that thermal boundary laver thickness and dynamic effects both contribute significantly to mantlederived elevation of the western U.S. Cordillera. The largest of the significant dynamic elevation anomalies is consistent with that predicted by numerical modeling of a Yellowstone hotspot swell. However, smaller-scale significant anomalies in the southern Basin-Range require some other mechanism. Possible mechanisms for the latter include superadiabatic upwelling and/or extension-driven (adiabatic) phase boundary deflections. The relative importance of various possible contributors to dynamic elevation remains uncertain. Estimation of the viscosity and effective activation energy of the lithosphere, performed to support the numerical modeling analysis, indicates that seismicity and volcanism are focused at boundaries separating lithosphere with negligible upper mantle viscosity from lithosphere with significant mantle viscosity. The mantle strength is controlled by intrinsic (material) properties in addition to transient thermal fields, suggesting that these boundaries could remain stationary on long timescales.

\section{Appendix A: Numerical Model of Dynamic Topography}

The numerical model of hotspot dynamics is similar to that of Ribe and Christensen [1999] with two significant differences. First, the surface velocity $U(x, t)$ can vary as a function of along-track position and time according to $U(x, t)=U_{0}+\int_{0}^{x} \dot{\epsilon} d x \equiv u_{s}(x, t)$, where $U_{0}$ is a reference velocity and $\dot{\epsilon}(x, t)$ is the extension rate in the plate motion direction. To first order, the strain rate is zero to the $\mathrm{NE}$ of Yellowstone and positive (extensional) to the SW. We therefore use the simple relations

$$
\begin{gathered}
\dot{\epsilon}=\frac{\dot{\epsilon}_{0}}{2} \exp \left[\left(x-x_{s}\right) / b\right] \quad\left(x \leq x_{s}\right) \\
\dot{\epsilon}=\dot{\epsilon}_{0}\left(1-\frac{1}{2} \exp \left[-\left(x-x_{s}\right) / b\right]\right) \quad\left(x>x_{s}\right)
\end{gathered}
$$

where $\dot{\epsilon}_{0}$ is a constant reference strain rate, $x_{s}(t) \equiv$ $x_{0}+U_{0} t$ is a moving reference point (approximately the $x$ coordinate of Yellowstone in the model box) and $b$ is the width of the zone of transition from unstrained (NE) to uniformly straining (SW) lithosphere.

Second, the lithosphere may have a nonuniform and time-varying thickness $l(x, y, t)$. Spatial variations in lithospheric thickness imply strong lateral viscosity variations near the base of the lithosphere. To model these, we multiply the viscosity predicted by equation (13) by the depth-dependent factor

$$
\Gamma=\frac{R+1}{2}-\frac{R-1}{2} \tanh \left[\frac{d_{3}-z-l(x, y, t)}{\delta}\right],
$$

where

$$
R=1+\left(R_{\max }-1\right) \tanh \left[\frac{l(x, y, t)-l_{\mathrm{ref}}(x, t)}{\delta}\right],
$$

and $R_{\max }$ is a maximum viscosity contrast, $\delta \ll l_{\min }$ is a vertical scale height, and $l_{\text {ref }}(x, t)$ is the normal lithospheric thickness that would occur in the absence of lateral variations in material properties. In essence, (A3) and (A4) correspond to multiplying the viscosity of the thickest parts of the lithosphere by a factor $R_{\max }$. Because the surface is undergoing both translation and extension, the lithospheric thickness $l(x, y, t)$ evolves with time according to

$$
\frac{\partial l}{\partial t}+\frac{\partial}{\partial x}[\dot{\epsilon}(x, t) l]=0
$$

subject to the condition $l(x, y, 0)=l_{p}(x, y)$, where $l_{p}(x, y)$ is the present-day lithospheric thickness determined by the procedure described in Appendix B. In actual practice, we first solve (A5) by itself backward in time to determine the thickness $l\left(x, y, t_{0}\right)$ at the chosen starting time $t_{0}$ and then use this thickness as the initial condition for integrating (A5) forward in time together with the equations for conservation of momentum and energy.

The numerical solutions described here were obtained using a grid spacing $\Delta x=\Delta y=16.7 \mathrm{~km}$ and a variable vertical grid spacing in a box of dimensions 1600 by 1600 by $400 \mathrm{~km}$. The values of all other model parameters are as by Ribe and Christensen [1994] except the reference plate velocity $U=1.1 \times 10^{-7} \mathrm{~m} \mathrm{~s}^{-1}\left(=3.5 \mathrm{~cm} \mathrm{yr}^{-1}\right)$ and the plume radius $a=68 \mathrm{~km}$.

\section{Appendix B: Estimation of Thickness of a Nonuniform Lithosphere}

To examine the influence of a nonuniform lithosphere on the Yellowstone swell, we first estimate a mechanical thickness $l$, defined as the depth to a reference effective viscosity. Lateral variations in $l$ depend on both temperature and material properties, so we constrain the lithospheric viscosity using both the thermal structure derived from equations (8)-(9) and lithospheric flexural rigidity $D$ (expressed in terms of $T_{e}$ in Plate 2). $T(z)$ 
and $D$ are mapped into $l$ using a yield strength envelope (YSE) approximation of rock strength properties [Goetze and Evans, 1979]. We assume that crustal and mantle strength layers are decoupled such that $D$ can be approximated by a "leaf-spring" model as $D=D_{m}+D_{c}$ [Burov and Diament, 1995] in which $D_{m}$ and $D_{c}$ are flexural rigidities of the mantle and crustal layers, respectively. Rigidities are given by

$$
D_{x}=-\frac{1}{C} \int_{z_{0}}^{z_{1}}\left[\sigma-\min \left(\sigma_{0}, \sigma_{\mathrm{YSE}}\right)\right]\left(z-z_{n}\right) d z
$$

in which the limits of integration $z_{0}$ and $z_{1}$ correspond to the top and bottom of the layer, $C$ is curvature of bending, $z_{n}$ is a neutral depth of bending defined such that

$$
\begin{array}{r}
\int_{z_{0}}^{z_{n}}\left[\sigma-\min \left(\sigma_{0}, \sigma_{\mathrm{YSE}}\right)\right]\left(z-z_{n}\right) d z= \\
\int_{z_{n}}^{z_{1}}\left[\sigma-\min \left(\sigma_{0}, \sigma_{\mathrm{YSE}}\right)\right]\left(z-z_{n}\right) d z,
\end{array}
$$

$\sigma_{0}$ is an in-plane (or tectonic) differential stress, $\sigma$ is the deviatoric stress in the lithosphere given by

$$
\sigma=\min \left\{\sigma_{\mathrm{YSE}},-\frac{E}{1-\nu^{2}} C\left(z-z_{n}\right)+\sigma_{0}\right\}
$$

$\sigma_{\mathrm{YSE}}$ is the yield strength envelope:

$$
\sigma_{\mathrm{YSE}}=\min \left\{\begin{array}{c}
\frac{-2 \mu\left(\mu+\sqrt{\mu^{2}-1}\right)}{\left(\sqrt{\mu^{2}-1}-\mu\right)^{2}} \rho g z(1-\lambda) \\
\left(\frac{\dot{\epsilon}}{A}\right)^{\frac{1}{n}} \exp \left(\frac{H^{*}}{n R T}\right)
\end{array}\right\},
$$

$E$ is Young's modulus, $\nu$ is Poisson's ratio, $\mu$ is the frictional coefficient of brittle failure, $\lambda$ is the pore pressure coefficient (expressed as a fraction of lithostatic pressure), .4 is the exponential coefficient of power law creep, $n$ is the exponential power, and other parameters are as previously defined in the paper. A sensitivity analysis of the parameters used in this calcula- tion demonstrates that all of these parameters have very slight effect on $D$, with the exceptions of temperature $T(z)$ and the material parameters of power law creep, $H^{*}$ and $A$, as previously suggested by Lowry and Smith [1995]. However. the same analysis also demonstrates that a lateral variation of either mantle activation energy $H_{m}^{*}$ or mantle power law coefficient $A_{m}$ is required to explain the relationship between observed variations in $D$ and $T(z)$, confirming earlier suggestions that variations in geotherm and crustal thickness are insufficient to explain the variability of flexural rigidity of continental lithosphere [Lowry and Smith, 1995; Hartley et al., 1996]. We fixed all parameters except $T(z)$ and $H_{m}^{*}$, using the values in Table $\mathrm{B} 1$, and used the crustal geotherm and a fixed crustal activation energy $H_{c}^{*}$ to estimate $D_{c}$ from (B1)-(B4). We then subtracted $D_{c}$ from the total rigidity $D$ and solved for $H_{m}^{*}$ that best approximated $D_{m}$ using a grid search algorithm. The effective viscosity $\eta(z)$ was calculated from the resulting yield strength envelope using

$$
\eta=\frac{\sigma_{\mathrm{YSE}}}{2 \dot{\epsilon}} .
$$

Lithospheric thickness $l(x, y)$ is defined for our purposes as the depth at which $\eta(z)=\eta_{r} \equiv 10^{21} \mathrm{~Pa} \mathrm{~s}$.

Some of the parameters that were held fixed in these calculations do vary, and errors in the assumed values will map into errors in the estimate of $\eta$. In particular, we note that reasonable variations in strain rate can change the estimate of $H_{m}^{*}$ by up $10 \%$, and variable $H_{c}^{*}, A_{m}$ and $A_{c}$ could change it even more. However, if we hold the mantle material parameters of power law creep to be everywhere constant in (B1)-(B4), there is no plausible combination of other variables that can reproduce the observed relationship between surface heat flow and $D$. We chose to fix $A_{m}$ in these calculations and let $H_{m}^{*}$ vary because of expectations that plausible variations in the activation energy would have the most significant effect on lithospheric strength. The estimates of $H_{m}^{*}$ resulting from this analysis range from 250 to $540 \mathrm{~kJ} \mathrm{~mol}^{-1}$; this range is consistent with the

Table B1. Parameters Used to Estimate Lithospheric Thickness $l$

\begin{tabular}{clcl}
\hline Parameter & \multicolumn{1}{c}{ Meaning } & Value & Units \\
\hline$C$ & curvature of bending & $10^{-9}$ & $\mathrm{~m}^{-1}$ \\
$\sigma_{0}$ & tectonic differential stress & 0 & $\mathrm{~Pa}$ \\
$E_{c}$ & crustal Young's modulus & $7 \times 10^{10}$ & $\mathrm{~Pa}$ \\
$E_{m}$ & mantle Young's modulus & $1.6 \times 10^{11}$ & $\mathrm{~Pa}$ \\
$\nu$ & Poisson's ratio & 0.25 & \\
$\mu$ & brittle frictional coefficient & 0.65 & \\
$\lambda$ & pore fluid pressure coefficient & 0.37 & \\
$A_{c}$ & crustal creep coefficient & $2 \times 10^{-4}$ & $\mathrm{~Pa} \mathrm{~s}^{n_{c}}$ \\
$A_{m}$ & mantle creep coefficient & $6 \times 10^{4}$ & $\mathrm{~Pa} \mathrm{~s}^{n_{m}}$ \\
$n_{c}$ & crustal creep exponent & 1.9 & \\
$n_{m}$ & mantle creep exponent & 3.5 & \\
$\dot{\epsilon}$ & strain rate & $10^{-16}$ & $\mathrm{~s}^{-1}$ \\
$H_{c}^{*}$ & crustal activation energy & $1.4 \times 10^{5}$ & $\mathrm{~J} \mathrm{~mol}^{-1}$ \\
\hline
\end{tabular}


range that would reasonably result from heterogeneities of grain size, partial melt, and/or volatile content of mantle aggregates [Poirier, 1991; Cooper and Kohlst$e d t, 1984]$. In spite of the uncertainties, the estimate of $l(x, y)$ derived here is certain to provide a much closer approximation of the real Earth than assumption of a uniform lithospheric thickness.

Acknowledgments. Some of the ideas presented in this paper crystallized from discussions with (but do not necessarily reflect the opinions of) John Bartley, Bruce Douglas, Ken Dueker, Craig Jones, Greg Overtoom, Martha Savage, Tim Stern, Mark Tamiseau, and Dick Walcott. The paper was greatly improved as a result of suggestions made by Michael Hamburger and referees Peter Bird and Brian Wernicke Figures were generated with GMT [Wessel and Smith, 1998]. This research was supported by NASA grant NAG5-7619 to A.R.L and NSF grants EAR 92-19694 to R.B.S. and EAR 92-04644 to N.M.R.

\section{References}

Anderson, R E., Tectonic evolution of the Intermontane System: Basin and Range, Colorado Plateau, and High Lava Plains, in Geophysical Framework of the Continental United States, edited by L. C. Pakiser and W. D. Mooney, Mem. Geol. Soc. Am., 172, 163-176, 1989.

Armstrong, R.L., W.P. Leeman, and H.E. Malde, K-Ar dating, Quaternary and Neogene volcanic rocks of the Snake River Plain, Idaho, Am. J. Scr., 275, 225-251, 1975.

Axen, G.J., W.J. Taylor, and J.M. Bartley, Space-time patterns and tectonic controls of Tertiary extension and magmatism in the Great Basin of the western United States, Geol. Soc. Am. Bull., 105, 57-76, 1993.

Bennett, R.A.. J.L. Davis, and B.P. Wernicke, Present-day pattern of Cordilleran defcrmation in the western United States, Geology, 27, 371-374, 1999.

Blackwell, D.D., J.L. Sreele, and L S Carter, Heat-flow patterns of the North American continent: A discussion of the geothermal map of North America, in Neotectonics of North America, Decade Map, vol. 1, edited by D. B. Slemmons et al., pp. 423-436, Geol. Soc. Am., Boulder, Colo., 1991

Bouhifd, M.A., D. Andrault, G. Fiquet, and P. Richet, Thermal expansion of forsterite up to the melting point, Geophys. Res. Lett., 23, 1143-1146, 1996.

Burke, K., and A. Whiteman, Uplift, rifting, and the breakup of Africa, in Implacations of Continental Drift to the Earth Scrences, vol. 2, edited by D.H. Tarling and S.K. Runcorn, pp. 735-755, Academic, San Diego, Calif, 1973.

Burov, E.B., and M. Diament, The effective elastic thickness of continental lithosphere: What does it really mean?, $J$. Geophys. Res., 100, 3905-3927, 1995.

Christensen, N.I., and W.D. Mooney, Seismic velocity structure and composition of the continental crust: A global view, J. Geophys. Res., 100, 9761-9788, 1995.

Christensen, U.R., Dynamic phase boundary topography with latent heat effects, Earth Planet. Sc2. Lett., 154, 295-306, 1998.

Christiansen, R.L., and P.W Lipman, Cenozoic volcanism and plate-tectonic evolution of the western United States, II, Late Cenozoic, Phllos. Trans. R. Soc. London, Ser. A, 271, 249-284, 1972.

Christiansen, R.L., and E H. McKee, Late Cenozoic volcanic and tectonic evolution of the Great Basin and Columbia Intermontane regions, in Cenozoic Tectonics and Regional Geophysics of the Western Cordullera, edited by R. B.
Smith and G. P. Eaton, Mem. Geol. Soc. Am., 152, 283-311, 1978.

Cooper, R.F., and D.L. Kohlstedt, Solution-precipitation enhanced diffusional creep of partially molten olivine-basalt aggregates during hot-pressing, Tectonophysics, 107, 207-233, 1984.

Crough, S.T., Hotspot swells, Annu. Rev. Earth Planet. Scı., 11, 165-193, 1983.

Davis, J.C., Statıstics and Data Analysis in Geology, 2nd ed., pp. 383-405, John Wiley, New York, 1986.

Dueker, K.G, and A.F. Sheehan, Mantle discontinuity structure from midpoint stacks of converted $P$ to $S$ waves across the Yellowstone hotspot track, J. Geophys. Res., 102, 8313-8327, 1997

Eaton, G P., The Basin and Range province: Origin and tectonic significance, Annu. Rev. Earth Planet. Sci., 10, 409-440, 1982.

Flesch, L.M., W.E. Holt, A.J. Haines, and B. Shen-Tu, Dynamics of the Pacific-North American plate boundary in the western United States, Scrence, 287, 834-836, 2000.

Fliedner, M.M., and S. Ruppert, Three-dimensional crustal structure of the southern Sierra Nevada from seismic fan profiles and gravity modeling, Geology, 24, 367-370, 1996.

Forsyth, D.W., Subsurface loading and estimates of the flexural rigidity of continental lithosphere, J. Geophys. Res., $90,12,623-12,632,1985$.

Fujii, T., and I. Kushiro, Density, viscosity and compressibility of basaltic liquid at high pressures, Year Book Carnegie Inst. Washington, 76, 419-424, 1977.

Geist, D., and M. Richards, Origin of the Columbia Plateau and Snake River Plain: Deflection of the Yellowstone plume, Geology, 21, 789-792, 1993.

Goetze, C., and B. Evans, Stress and temperature in the bending lithosphere as constrained by experimental rock mechanics, Geophys. J. R. Astron. Soc., 59, 463-478, 1979.

Hartley, R., A.B Watts, and J.D. Fairhead, Isostasy of Africa, Earth Planet. Scı. Lett., 137, 1-18, 1996.

Hoffman, P.F., Precambrian geology and tectonic history of North America, in The Geology of North America, vol. A, The Geology of North America: An Overvew, edited by A.W. Balley and A.R. Palmer, pp. 447-512, Geol. Soc. Am., Boulder, Colo., 1989.

Hofmeister, A.M., Mantle values of thermal conductivity and the geotherm from phonon lifetimes, Science, 283, 1699-1706, 1999

Humphreys, E.D., and K.G. Dueker, Physical state of the western U.S. upper mantle, J. Geophys. Res., 99, 9635$9650,1994$.

Jones, C.H., B.P. Wernicke, G.L. Farmer, J.D Walker, D.S. Coleman, L.W. McKenna, and F.V. Perry, Variations across and along a major continental rift: An interdisciplinary study of the Basin and Range province, western USA, Tectonophysıcs, 213, 57-96, 1992.

Jones, C.H., J.R. Unruh, and L.J. Sonder, The role of gravitational potential energy in active deformation in the southwestern United States, Nature, 381, 37-41, 1996.

Jordan, T.H., Composition and development of the continental lithosphere, Nature, 274, 544-548, 1978

Jordan, T H., Continents as a chemical boundary layer, Philos. Trans. R. Soc. London, Ser. A, 301, 359-373, 1981.

Katsura, T., Thermal diffusivity of olivine under upper mantle conditions, Geophys. J. Int., 122, 63-69, 1995.

Kukkonen, I.T., J. Jokinen, and U. Siepold, Temperature and pressure dependencies of thermal properties of rocks: Implications for uncertainties in thermal lithosphere models and new laboratory measurements of high-grade rocks in the central Fennoscandian Shield, Surv. Geophys., 20, 33-59, 1999. 
Lachenbruch, A.H., and J.H. Sass, Models of an extending lithosphere and heat flow in the Basin and Range province, in Cenozorc Tectonucs and Regional Geophysics of the Western Cordullera, edited by R.B. Smith and G.P. Eaton, Mem. Geol. Soc. Am., 152, 209-250, 1978.

Lachenbruch, A.H., J.H. Sass, and P. Morgan, Thermal regime of the southern Basin and Range province, 2, Implications of heat flow for regional extension and metamorphic complexes, J. Geophys. Res., 99, 22,121-22,133, 1994.

Lowry, A.R., and R.B. Smith, Flexural rigidity of the Basin and Range-Colorado Plateau-Rocky Mountain transition from coherence analysis of gravity and topography, J. Geophys. Res., 99, 20,123-20,140, 1994.

Lowry, A.R., and R.B. Smith, Strength and rheology of the western U. S. Cordillera, J. Geophys. Res., 100, 17,94717,963, 1995.

Mabey, D.R., Geophysics and tectonics of the Snake River Plain, Idaho, in Cenozoic Geology of Idaho, edited by B. Bonnichsen and R.M. Breckenridge, Bull. Idaho Bur. Mines Geol., 26, 139-153, 1982

Mareschal, J.C., and G. Bergantz, Constraints on thermal models of the Basin and Range province, Tectonophysics, $174,137-146,1990$

Mareschal, J.C., J.P. Cunningham, and R.P. Lowell, Downward continuation of heat flow data, method and examples for the western U.S., Geophysics, 50, 846-851, 1985.

Matsui, M., Computer simulation of the $\mathrm{Mg}_{2} \mathrm{SiO}_{4}$ phases with application to the $410 \mathrm{~km}$ seismic discontinuity, Phys. Earth Planet. Inter., 116, 9-18, 1999.

McKenzie, D., Some remarks on the development of sedimentary basins, Earth Planet. Sci. Lett., 40, 25-32, 1978.

McKenzie, D., and M.J. Bickle, The volume and composition of melt generated by extension of the lithosphere, $J$. Petrol., 29, 625-679, 1988.

McQuarrie, N., and D.W. Rogers, Subsidence of a volcanic basin by flexure and lower crustal flow: The eastern Snake River Plain, Idaho, Tectonics, 17, 203-220, 1998.

Morgan, P., Estimates of mantle thermal conductivity based on high-temperature measurements of mantle xenolith conductivities (abstract), Eos Trans. $A G U, 74(43)$, Fall Meet. Suppl., 597, 1993.

Pari, G., and W.R. Peltier, Subcontinental mantle dynamics: A further anlysis based on the joint constraints of dynamic surface topography and free-air gravity, J. Geophys. Res., 105, 5635-5662, 2000.

Park, S.K., B. Hirasuna, G.R. Jiracek, and C. Kinn, Magnetotelluric evidence of lithospheric mantle thinning beneath the southern Sierra Nevada, J. Geophys. Res., 101, 16,241-16,255, 1996.

Parsons, T., G.A. Thompson, and N.H. Sleep, Mantle plume influence on the Neogene uplift and extension of the U.S. western Cordillera?, Geology, 22, 83-86, 1994.

Pierce, K.L., and L.A. Morgan, The track of the Yellowstone hotspot. Volcanism, faulting and uplift, U.S. Geol. Surv. Open File Rep., 90-415, 1-48, 1990.

Podladchikov, Y.Y., A.N.B. Poliakov, and D.A. Yuen, The effect of lithospheric phase transitions on subsidence of extending continental lithosphere, Earth Planet. Sci. Lett., 124, 95-103, 1994.

Poirier, J.P., Introduction to the Physics of the Earth's Interior, 264 pp., Cambridge Univ. Press, New York, 1991.

Pollack, H.N., S.J. Hurter, and J.P. Johnson, Heat flow from the Earth's interior: Analysis of the global data set, Rev. Geophys., 31, 267-280, 1993

Presnall, D.C., J.R. Dixon, T.H. O'Donnell, and S.A. Dixon, Generation of midocean ridge tholeiites, J. Petrol., 20, 335, 1979.

Reynard, B., and G.D. Price, Thermal expansion of mantle minerals at high pressures-a theoretical study, Geophys. Res. Lett., 17, 689-692, 1990.

Ribe, N.M., and U. Christensen, Three-dimensional modeling of plume-lithosphere interaction, J. Geophys. Res., 99, 669-682, 1994.

Ribe, N. M. and Christensen, U., The dynamical origin of Hawairan volcanism, Eorth Planet. Scl. Lett., 171, 517531,1999

Saltus, R.W., and G.A. Thompson, Why is it downhill from Tonopah to Las Vegas? A case for mantle plume support of the high northern Basin and Range, Tectonics, 14, 1235-1244, 1995.

Savage, M.K., and A F. Sheehan, Seismic anisotropy and mantle flow from the Great Basin to the Great Plains, western United States, J. Geophys. Res., 105, 13,715$13,734,2000$.

Şengör, A.M.Ç., and K. Burke, Relative tıming of rifting and volcanism on Earth and its tectonic implications, Geophys. Res. Lett., 5, 419-421, 1978.

Shen-Tu, B., W.E. Holt, and A.J. Haines, Contemporary kinematics of the western United States determined from earthquake moment tensors, very long baseline interferometry, and GPS observations, J. Geophys. Res., 103, 18,087-18,117, 1998.

Siepold, U., Temperature dependence of thermal transport properties of crystalline rocks-A general law, Tectonophysics, 291, 161-171, 1998.

Sleep, N., Lateral flow and ponding of starting plume material, J. Geophys. Res., 102, 10,001-10,012, 1997.

Smith, R.B., Seismicity, crustal structure, and intraplate tectonics of the interior of the western Cordillera, in Cenozorc Tectonics and Regronal Geophysics of the Western Cordillera, edited by R.B Smith and G.P. Eaton, Mem. Geol. Soc. Am., 152, 111-144, 1978.

Smith, R.B., and L.W. Braile, The Yellowstone hotspot, J. Volcanol. Geotherm. Res., 61, 121-187, 1994.

Smith, R.B., W.C. Nagy, K.A. Julander, J.J. Viveiros, C.A Barker, and D.G. Gants, Geophysical and tectonic framework of the eastern Basin and Range-Colorado PlateauRocky Mountain transition, in Geophysical Framework of the Continental United States, edited by L.C. Pakiser and W.D. Mooney, Mem. Geol. Soc. Am., 172, 205-233, 1989.

Sonder, L.J., P.C. England, B.P. Wernicke, and R.L. Christiansen, A physical model for Cenozoic extension of North America, in Contrnental Extensional Tectonics, edited by M.P. Coward, J.F. Dewey and P.L. Hancock, Geol. Soc. Spec. Publ., 28, 187-200, 1987

Stolper, E., D. Walker, B.H Hager, and J.F. Hays, Melt segregation from partially molten source regions: The importance of melt density and source region size, J. Geophys. Res., 86, 6261-6271, 1981.

Suppe, J., C. Powell, and R. Berry, Regional topography, seismicity, Quaternary volcanism, and the present-day tectonics of the western United States, Am. J. Scı., 275A, 397-436, 1975.

Tackley, P.J, and D.J. Stevenson, A mechanism for spontaneous self-perpetuating volcanism on the terrestrial planets, in Flow and Creep in the Solar System: Observatrons, Modeling and Theory, edited by D. B. Stone and S. K. Runcorn, pp 307-321, Kluwer Acad., Norwell, Mass., 1993.

Turcotte, D.L., and G. Schubert, Geodynamics: Applications of Continuum Physics to Geological Problems, pp. 251-257, John Wiley, New York, 1982.

U.S. Geological Survey, Digital elevation models, data user guide 5, Reston, Va., 50 pp., 1993.

Waschbusch, P.J., and M.K. McNutt, Yellowstone: A continental midplate (hotspot) swell, Geophys. Res. Lett., 21, 1703-1706, 1994 
Watson, S., and D. McKenzie, Melt generation by plumes; a study of Hawaiian volcanism, Terra Nova Abstr., 3, 418, 1991.

Watts, A.B., Gravity and bathymetry in the central Pacific Ocean, J. Geophys. Res., 81, 1533-1553, 1976.

Wernicke, B.P., R.L. Christiansen, P C England, and L.J. Sonder, Tectonomagmatic evolution of Cenozoic extension in the North American Cordillera, in Contunental Extensional Tectonıcs, edited by M.P. Coward, J.F. Dewey and P.L. Hancock, Geol. Soc. Spec. Publ., 28, 203-221, 1987.

Wernicke, B.P., G.J. Axen, and J.K. Snow, Basin and Range extensional tectonics at the latitude of Las Vegas, Nevada, Geol. Soc. Am. Bull., 100, 1738-1757, 1988.

Wernicke, B.P., et al., Origin of high mountains in the continents: The southern Sierra Nevada, Science, 271, 190-193, 1996.

Wessel, P., and W. H. F. Smith, New, improved version of Generic Mapping Tools released, Eos Trans. AGU, $79(47), 579,1998$.
Wilson, J.T., A possible origin of the Hawaiian Islands, Can. J. Phys., 41, 863-870, 1963

Zoback, M.L., E.H. McKee, R J. Blakely, and G.A. Thompson, The northern Nevada rift: Regional tectono-magmatic relations and middle Miocene stress direction, Geol. Soc. Am. Bull., 106, 371-382, 1994.

A. R. Lowry, Department of Physics, Campus Box 390, Colorado University, Boulder, CO 80309-0390. (arlowry@valdemar.colorado.edu)

N. M. Ribe, Laboratoire de Dynamique des Systemes Geologie, IPG, 4 Place Jussieu, 75252 Paris cedex 05, France. (ribe@ipgp.jussieu.fr)

R. B. Smith, Department of Geology and Geophysics, University of Utah, Salt Lake City, UT 84112-1183. (rbsmith@mines.utah.edu)

(Received August 26, 1999; revised April 24, 2000; accepted May 22, 2000.) 